\title{
Ferulated Arabinoxylans and Their Gels: Functional Properties and Potential Application as Antioxidant and Anticancer Agent
}

\author{
Mayra Alejandra Mendez-Encinas, ${ }^{1}$ Elizabeth Carvajal-Millan $\mathbb{D}^{1},{ }^{1}$ Agustín Rascon-Chu, ${ }^{2}$ \\ Humberto Francisco Astiazaran-Garcia, ${ }^{3}$ and Dora Edith Valencia-Rivera ${ }^{4}$ \\ ${ }^{1}$ Biopolymers, Research Center for Food and Development, CIAD, A.C. Carretera a La Victoria Km. 0.6, 83304 Hermosillo, \\ SON, Mexico \\ ${ }^{2}$ Biotechnology, Research Center for Food and Development, CIAD, A.C. Carretera a La Victoria Km. 0.6, 83304 Hermosillo, \\ SON, Mexico \\ ${ }^{3}$ Nutrition, Research Center for Food and Development, CIAD, A.C. Carretera a La Victoria Km. 0.6, 83304 Hermosillo, SON, Mexico \\ ${ }^{4}$ Department of Chemical Biological and Agropecuary Sciences, University of Sonora, Avenida Universidad e Irigoyen, \\ 83621 Caborca, SON, Mexico
}

Correspondence should be addressed to Elizabeth Carvajal-Millan; ecarvajal@ciad.mx

Received 12 December 2017; Revised 19 May 2018; Accepted 2 July 2018; Published 16 August 2018

Academic Editor: Jaideep Banerjee

Copyright (C) 2018 Mayra Alejandra Mendez-Encinas et al. This is an open access article distributed under the Creative Commons Attribution License, which permits unrestricted use, distribution, and reproduction in any medium, provided the original work is properly cited.

In the last years, biomedical research has focused its efforts in the development of new oral delivery systems for the treatment of different diseases. Ferulated arabinoxylans are polysaccharides from cereals that have been gaining attention in the pharmaceutical field due to their prebiotic, antioxidant, and anticancer properties. The antioxidant and anticancer properties of these polysaccharides make them attractive compounds for the treatment of cancer, particularly colon cancer. In addition, ferulated arabinoxylans can form covalent gels through the cross-linking of their ferulic acids. Due to their particular characteristics, ferulated arabinoxylan gels represent an excellent alternative as colon-targeted drug delivery systems. The aim of the present work is to review the physicochemical and functional properties of ferulated arabinoxylans and their gels and to present the future perspectives for potential application as antioxidant and anticancer agents.

\section{Introduction}

Consumption of whole grains is associated with the prevention of cardiovascular diseases, diabetes, obesity, and cancer [1]. The dietary fiber and the antioxidant compounds of grains play an important role providing such benefits.

An inverse relationship between the dietary fiber of whole grain consumption and total cancer death has been established [2]. Particularly, a case study suggested that higher intake of dietary fiber reduces the risk of incident colorectal adenoma and distal colon cancer [3]. In addition, dietary fiber has shown to reduce type 2 diabetes mellitus risk through glycemic control or decrease energy intake, reduce blood glucose excursions, and lower insulin responses [4]. Moreover, insoluble antioxidants of whole grains which are bounded to arabinoxylan side chains can be released by microbial enzymatic hydrolysis in the colon and adsorbed, exhibiting an antioxidant protection [1]. On the other hand, certain components of dietary fiber such as arabinoxylans (AX) have prebiotic properties. In fact, phenolic acids of AX, such as ferulic acid (FA), exert antioxidant activity [5]. In this way, AX have gained attention in the pharmaceutical field due to their interesting functional and biological properties.

AX are nonstarch polysaccharides in the cell wall of cereal grains. A unique property of AX is their ability to form covalent gels by the oxidative coupling of the FA [6]. Due to their covalent nature, these gels have interesting characteristics such as high water absorption capacity and stability to $\mathrm{pH}$, temperature, and ionic charges [7]. In addition, AX gels exhibit antioxidant activity [8] and can be fermented by the 
colonic microbiota [9-11]. Furthermore, several studies have demonstrated the biological properties of AX, particularly their prebiotic, antioxidant, and more recently anticancer properties [12-16]. The anticancer activity of AX has been largely related to their prebiotic and antioxidant properties [17-19]. Thus, the particular characteristics and functional properties of AX make them promising polysaccharides for biopharmaceutical purposes.

The prebiotic and antioxidant properties of AX depend on its structural characteristics. It has been established that the presence and appearance of FA in AX impacts directly in its antioxidant and prebiotic properties [20]. A previous study showed that highly feruloylated AX oligosaccharides (AXOS), hydrolytic degradation products of AX, were less fermented than AXOS depleted in FA [20]. This appears to be a great advantage due to the selective inhibition of the growth of certain nonbeneficial bacteria, but the growth of probiotic bacteria, such as Lactobacillus and Bifidobacterium, which are able to produce FA esterases to release FA from AXOS and AX [21, 22]. In addition, the presence and amount of FA result to be the principal factor in providing the antioxidant capacity to AX and AXOS as has been well documented previously $[10,20]$. Then, it could be interesting to investigate how the cross-linking of $\mathrm{AX}$ could impact on the prebiotic and antioxidant properties of $\mathrm{AX}$ gels.

Recently, researchers have focused their attention on the development of novel bioactive materials as colon-targeted oral delivery systems for the treatment of diseases such as colon cancer $[23,24]$. AX gels with anticancer activity could be potential candidates for use as matrices for drug delivery in the treatment of colon cancer. AX with a high content of FA lead to the formation of high cross-linked density gels [25]. Since AX exhibit anticancer activity, the effect of the oxidative gelation and the cross-linking density of the gels on such property need to be investigated. In this context, the objective of the present review focuses on the functional and biological properties of $\mathrm{AX}$ and their gels and their potential application as antioxidant and anticancer agents.

\section{Arabinoxylans}

2.1. Chemical Structure. AX are polysaccharides from cereal grains constituted by a linear $\beta$-(1-4)-xylopyranosyl chain. Some $\alpha$-L-arabinofuranosyl residues are linked to the main xylose chain at O-3 and/or O-2 positions, resulting in four different structures (monosubstituted at O-3 or O-2, disubstituted at O-2,3, and unsubstituted) (Figure 1(b)). The amount and distribution of these branches can vary depending on the source of the polysaccharide [26]. In addition to arabinose, some galactose, xylose, and glucuronic acid residues can exist as side branches in the main chain of AX [27].

A particular structural characteristic of AX is the presence of phenolic acids. Some FA and cumaric acid residues can be esterified to arabinose at the O-5 position [28] (Figure 1(a)). FA is the most abundant phenolic acid in AX, and its content depends on the origin of the tissue (Table 1). AX from endosperm contains very small amounts of FA, while AX from pericarp and aleurone layer are highly esterified to FA [20]. The FA contents in AX vary from 0.001 to $7.00 \mu \mathrm{g} / \mathrm{mg}$ AX $[29,30]$. High contents of FA $(6-7.00 \mu \mathrm{g} / \mathrm{mg} \mathrm{AX})$ have been detected in maize bran AX $[25,30]$, while AX extracted from finger millet bran and ispaghula seed contain very low or even undetectable amounts of FA $(0.001 \mu \mathrm{g} / \mathrm{mg}$ AX) $[29,31]$. These differences could be related to the source of the polysaccharide as well as the method used for its extraction.

Usually, the structure of AX in different cereal tissues is similar, although some differences in the fine structure can drastically modify its functional properties. These differences are reflected in the degree of polymerization (DP), arabinoxylan to xylose ratio (A/X), amount and sequence of glycosidic bonds, and the presence of other substituents [7]. AX can be classified according to their solubility in aqueous solvents as water-extractable (WE-AX) and water-unextractable (WUAX) AX. In cereals, the cross-linking between AX and other components from the cell wall form structures that are insoluble in water. Alkali treatments are used to hydrolyze such cross-links, allowing the release of AX chains from the cell wall and making them soluble in the aqueous environment [27].

The substitution degree in the AX structure can be determined by the $\mathrm{A} / \mathrm{X}$. The $\mathrm{A} / \mathrm{X}$ may vary from 0.3 to 1.1 in $\mathrm{AX}$ from different cereals depending on the origin of the polysaccharide; $\mathrm{AX}$ from pericarp present higher $\mathrm{A} / \mathrm{X}$ values than those for endosperm or aleurone layer [46, 47]. However, this parameter does not describe detailed and exhaustive structural characteristics of $\mathrm{AX}$, and therefore, it cannot be used to characterize its fine structure.

The molecular weight $(\mathrm{Mw})$ of $\mathrm{AX}$ can vary depending on the polysaccharide origin and the method used for its determination. The average $\mathrm{Mw}$ estimated for $\mathrm{AX}$ ranges from 10 to $10,000 \mathrm{kDa}$ [7]. The $\mathrm{Mw}$ and the $\mathrm{Mw}$ distribution (polydispersity index (PI)) of AX can be affected by the extraction conditions (time, $\mathrm{pH}$, and temperature) [48].

2.2. Physicochemical Characteristics. AX show physicochemical characteristics, such as solubility and viscosity, which provide them different functional properties. Similar to other polysaccharides, the water solubility of AX depends on certain parameters such as the chain-chain and chain-solvent interactions. In addition, some structural factors including the chain length and the presence and distribution of side groups can also modify the solubility of the polymers. The substitution pattern of the polysaccharide chain is the main parameter controlling the solubility of AX. Since the mechanism of aggregation in the AX is due to the intermolecular interactions of the unsubstituted regions of the polysaccharide chain, the presence of arabinose residues in the xylose chain is determinant for the solubility of AX [48].

AX form very high viscous solutions in aqueous environments. The apparent viscosity of the AX solutions is concentration- and shear rate-dependent. The viscosity values increase as the polymer concentration increases, and decrease as the shear rate increases [27]. The $\mathrm{Mw}$ is another important factor that determines the viscosity of the AX solutions. Izydorczyk and Biliaderis [49] demonstrated that wheat AX solutions with high Mw fractions showed weak 


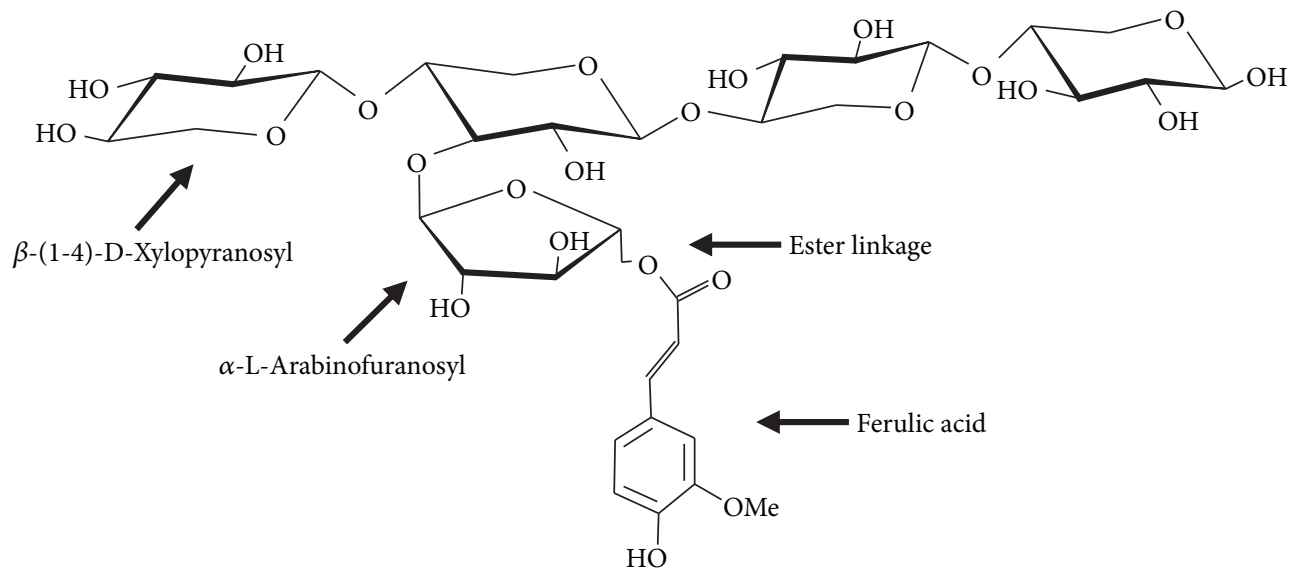

(a)

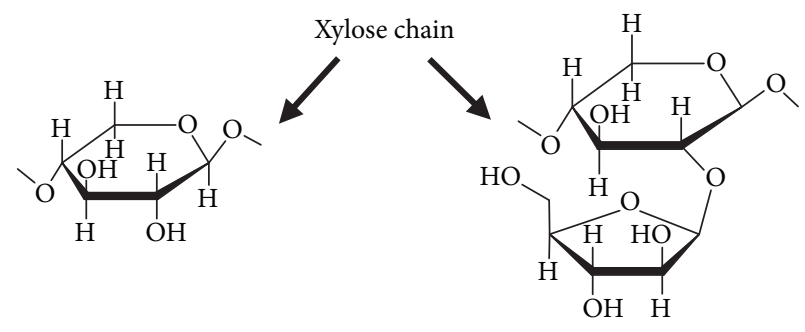

Unsubstituted

Monosubstituted at O-2

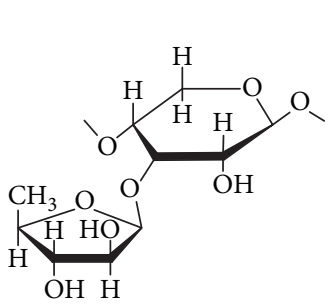

Monosubstituted at O-3

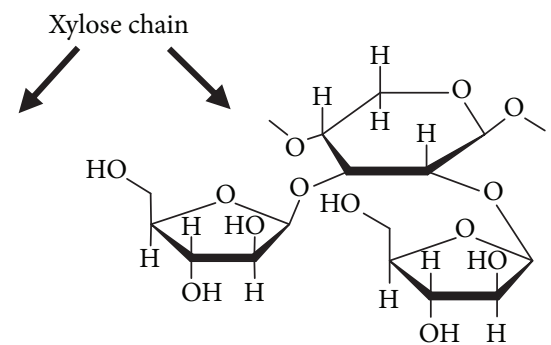

Disubstituted at O-2,3

(b)

Figure 1: (a) Chemical structure of AX and (b) arabinose substitution in AX chain.

elastic properties. The viscous behavior of AX solutions is the most important characteristic responsible for the functional properties that AX exhibit in the human gastrointestinal tract [27].

2.3. Functional Properties. Functional properties of AX such as prebiotic, antioxidant, and anticancer as well as its gelling capacity result to be of great interest for biomedical and pharmaceutical applications. Therefore, research has focused its efforts on exploiting different sources of $\mathrm{AX}$ in order to explore and take advantage of such properties for several applications (Table 1). Maize, wheat, and rice are the main sources of $\mathrm{AX}$ which have been investigated for biomedical and pharmaceutical applications. Maize and wheat AX gels have shown promising results for their potential application as controlled-release matrices [11, $32-35,37]$. On the other hand, the use of $\mathrm{AX}$ from rice bran has been widely investigated as an adjuvant in cancer immunotherapy [41, 42].

2.3.1. Prebiotic. The products of AX degradation have been of great interest due to their prebiotic properties. Prebiotics are defined as "a non digestible compound that, through its metabolization by microorganisms in the gut, modulates the composition and/or activity of the gut microbiota, thus conferring a beneficial physiological effect on the host" [50]. AX are resistant to gastric acid, proteolytic enzymes, and absorption in the stomach or small intestine. In addition, $\mathrm{AX}$ are fermented by the gut microbiota and selectively stimulate the growth and/or activity of beneficial bacteria in the colon, so they may be considered as prebiotics.

AX stimulate the growth of beneficial bacteria for the gastrointestinal tract. In vivo assays have demonstrated that AX 
TABle 1: Origin, FA content, and current/potential application of AX in biomedical and pharmaceutical fields.

\begin{tabular}{|c|c|c|c|}
\hline AX origin & FA content $(\mu \mathrm{g} / \mathrm{mg} \mathrm{AX})$ & Currently/potential application in biomedical/pharmaceutical field & Reference \\
\hline Nejayote/maize bran & $0.012 / 0.025$ & Entrapment of probiotic & {$[32]$} \\
\hline Nejayote/maize bran & $0.012 / 0.025$ & $\begin{array}{l}\text { Entrapment and controlled release of insulin and } \\
\text { probiotics targeted to colon }\end{array}$ & {$[11]$} \\
\hline Maize bran & 0.34 & Controlled release of insulin and $\beta$-lactoglobulin & [33] \\
\hline Maize bran & 0.25 & Controlled release of insulin targeted to colon & [34] \\
\hline Maize bran & 4.0 & Entrapment and controlled release of methyl xanthine & {$[35]$} \\
\hline Wheat endosperm & 2.3 & Controlled release of proteins & {$[36]$} \\
\hline Wheat endosperm & 0.53 & Entrapment of probiotics & [37] \\
\hline Wheat bran & 0.435 & Antitumor and immunomodulatory activity & {$[16,38]$} \\
\hline Wheat bran & - & Prebiotic & [39] \\
\hline Rice bran & - & Antitumor and immunomodulatory activity & {$[40]$} \\
\hline Rice bran (MGN-3/Biobran) & - & $\begin{array}{c}\text { Cancer immunotherapy } \\
\text { Prevention and inhibition of cancer } \\
\text { Synergistic effect with chemotherapeutic agents }\end{array}$ & {$[15,41,42]$} \\
\hline Finger millet bran & 0.001 & Immunomodulatory activity & {$[29]$} \\
\hline Ispaghula (Plantago ovata) seed & nd & Drug carrier & {$[31,43]$} \\
\hline Ispaghula (Plantago ovata) seed & - & Controlled release of mucoadhesive oral films & {$[44,45]$} \\
\hline
\end{tabular}

nd: no detectable; -: no reported.

promote the growth of Bifidobacterium and Lactobacillus, both considered as beneficial species for the gut [51]. These modifications in the gut microbiota are associated with health benefits, reduction in gastrointestinal infections, and improvement in the mineral absorption and the suppression of colon cancer $[52,53]$.

It has been established that some phenolic acids modulate the composition of microbiota through the selective inhibition of some pathogenic bacteria, while the growth of commensal anaerobes and probiotic bacteria is less affected or even increased $[22,54]$. In this regard, the growth of probiotic such as Bifidobacterium and Lactobacillus during AX fermentation can be explained by the fact that these bacteria produce the $\mathrm{FA}$ esterases to release the $\mathrm{FA}$ residues from AX [21, 55, 56].

Another benefit of $\mathrm{AX}$ as a prebiotic is the production of beneficial bacterial metabolites, such as short-chain fatty acids (SCFA). The fermentation of AX increases the production of acetic, propionic, and butyric acids. Particularly, AX are characterized by increasing the butyric acid levels, which play an important role in the maintenance of health and gastrointestinal function [57]. The fermentation of AX is associated with the growth of butyric acid-producing bacteria, such as Eubacterium and Roseburia [58]. Nielsen et al. [59] evaluated the effect of AX-rich and high-fat diets on the production of SCFA in pigs. The supplementation of the AX-rich diet increased the SCFA levels, particularly the butyric acid level which was 5 -fold higher compared with that obtained for the high-fat diet.

Butyric acid is considered an essential metabolite for the human colon as it is the main source of energy for its epithelial cells (colonocytes), contributes to the maintenance of the gut barrier functions, and has immunomodulatory and anti- inflammatory properties [58]. In addition, the proliferation of butyrate-producing bacteria protects the colon from pathogenic microbiota [60]. For those reasons, AX have been considered as polysaccharides with excellent prebiotic properties. The consumption of this polysaccharide provides many health benefits, especially those related with the prevention of colon cancer.

Recently, long-chain AX (LC-AX) have demonstrated to modulate the luminal and mucosal microbiota. Experiments using a dynamic in vitro model of the human digestive tract (M-SHIME) showed that supplementation of LC-AX to the proximal colon compartments of the M-SHIME increased Bifidobacterium population in both lumen and mucus compared with the control. The levels of propionate as well as the activity of enzymes $\beta$-xylanase, $\beta$-xylosidase, and $\alpha$-arabinofuranosidase were also increased in the lumen region. These findings suggest that LC-AX could exert a potential prebiotic effect on the host, as the mucosa-associated microbiota impacts directly in health by protecting against pathogen colonization and host immunity [61].

2.3.2. Antioxidant. The antioxidant activity of AX has been mainly associated with their content of phenolic acids, particularly FA. Phenolic acids have beneficial effects against chronic and cardiovascular diseases, cancer, diabetes, inflammatory diseases, and aging [62]. Phenolic acids exhibit their antioxidant activity through diverse mechanisms such as free radical scavenging, metal chelation, and reducing potential, blocking the free radical chain, modulation of enzymatic activity, and alteration of signal transduction pathways [63-65].

The main function of antioxidants is delaying or prevention of the oxidation produced by free radicals [66]. The free 
radicals are generated by diverse factors such as normal metabolic activity, diet, and environment. In a natural manner, the body uses antioxidant endogenous enzymes as a defense mechanism against the free radicals. An increase in the production of free radicals and other reactive oxygen species exceeding normal levels in the body results in oxidative stress. This imbalance causes damage to biomolecules such as membrane lipids, lipoproteins, and DNA, increasing the risk of developing chronic diseases [67]. Therefore, the use of antioxidants results to be adequate to decrease the effects of free radicals and the risk of chronic diseases, such as cancer.

Although the antioxidant activity of AX is associated with the presence of phenolic acids, some studies suggest that this activity is mainly attributed to FA. The antioxidant activity of FA is attributed to its structural characteristics. The presence of electron-donating groups on its benzene ring gives it the property of terminating the free radical chain reactions. In addition, its $\mathrm{COOH}$ - group can bind to the lipid bilayer, providing protection against the free radicals attack and the lipid peroxidation [62]. Since FA is the most abundant phenolic acid in AX, it may be the main responsible for the antioxidant activity of the polysaccharide, as has been observed in different studies.

Recently, Kamboj and Rana [68] compared the antioxidant activity of maize bran gum with the antioxidant activity from other natural gums as xanthan and guar gums. They found that the maize fiber gum exhibited a higher antioxidant activity compared to the other gums, regardless of the method used for the determination. They suggested that maize fiber gum could be a promising excipient with antioxidant activity in the food and pharmaceutical industry.

Feruloyl oligosaccharides (FOS), hydrolytic products of AX, exhibit a protective effect on the cells against the damage produced by the free radicals. Wang et al. [14] evaluated the protective effect of FOS against the oxidative stress in rat plasma. The levels of oxidized glutathione and malondialdehyde and the activity of antioxidant enzymes in plasma from rats fed with the FOS diet decreased with respect to the control group. In a previous study, the protective activity of FOS against the oxidative DNA damage in normal human lymphocytes induced by hydrogen peroxide was investigated. The DNA damage was inhibited by FOS, observing a $91 \%$ inhibition of lymphocyte DNA damage at $500 \mu \mathrm{mol} / \mathrm{L}$ as compared with control [69].

The content and appearance of FA determine the antioxidant capacity of AX. Higher contents of trimers of FA (triFA) in AX result in higher antioxidant activity [5]. This behavior is attributed to three units of FA, which provide higher amounts of $\mathrm{OH}-$ groups, increasing the hydrogen donor capacity and, therefore, protecting from radical scavenging [70]. This highlights the close relationship existing between the structural characteristics of the polysaccharide and its functional properties. Therefore, when discussing about the antioxidant capacity of AX, not only the FA content should be considered but also how it is found in the molecule. The knowledge of such structural characteristics would help to predict the antioxidant activity of AX in order to consider it for specific applications.
2.3.3. Anticancer. Cancer is among the leading causes of death worldwide, and the second most common in the United States [71]. Usually, conventional cancer treatments including surgery, chemotherapy, and radiotherapy which focus on eliminating cancer cells are short-term effective, but not enough for a complete eradication of all cancer cells, resulting in recurrence of disease [72]. The repeated sessions of treatments lead to the suppression of the immune system and promote multidrug resistance and toxicity $[41,73]$. Therefore, the search for natural products with chemopreventive properties and without side effects has been increasing.

AXOS exhibit protective effects against colon cancer, which have been related to their prebiotic effect. Femia et al. [17] observed that the administration of AXOS reduced the preneoplastic lesions in the colon of rats. The authors suggest that AXOS exhibited a chemopreventive effect on colon carcinogenesis due to their prebiotic activity. On the other hand, Glei et al. [74] showed that the fermentation products of wheat AX (SCFA) inhibited the growth of colon cancer cells (HT29) and induced the antioxidant activity of the endogenous enzyme glutathione transferase.

A close relationship between the proliferation of cancer cells and the antioxidant systems has been suggested. Cancer cells produce large amounts of hydrogen peroxide, which may favor mutations, damage, and invasion of other tissues. Then, cancer cell proliferation impacts directly in the antioxidant machinery, and according to this, some anticancer agents can act as antioxidants [19]. Thus, the antitumor potential of AX has been related to its antioxidant effect. Noaman et al. [19] supplied AX from rice to rats, which were previously inoculated with Erlich cancer cells. The results showed the inhibition of the development and growth of tumors, as well as a decrease in lipid peroxidation and increase in the activity of endogenous antioxidant enzymes (catalase, superoxide dismutase, and glutathione transferase). The authors suggested that AX exerted an antioxidant effect through its ability to increase the gene expression and activity of endogenous antioxidant enzymes in the cells and normalize the lipid peroxidation in blood, liver, and tumor tissue in animals bearing tumors.

In a previous study, the antitumor activity of MGN-3/ Biobran on mice bearing a solid Erlich carcinoma (SEC) tumor was attributed to mechanisms involving induction of apoptosis and immune modulation. The administration of MGN-3 significantly decreased tumor volume (63.27\%) and tumor weight (45.2\%) in comparison to the control group. Flow cytometry and histopathological analyses showed an increase in the number of apoptotic SEC cells. In addition, an improvement of cytokine production was observed as shown by increasing levels of tumor necrosis factor- $\alpha$ and interferon- $\gamma$, while the levels of immune suppressing IL-10 were downregulated. In addition, the activity of natural killer (NK) cells was also increased [75].

The synergistic anticancer effect of MGN-3/Biobran with natural anticancer agents as well as chemotherapeutic drugs has been widely explored using in vitro studies. The synergistic apoptotic potential of MGN-3 and curcumin on human multiple myeloma cell line U266 was determined. Treatment 


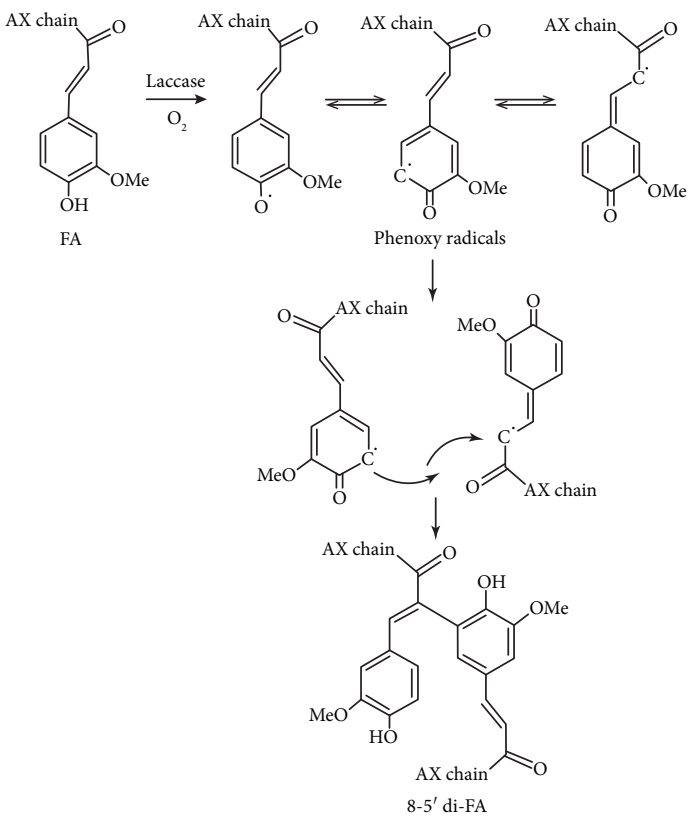

(a)

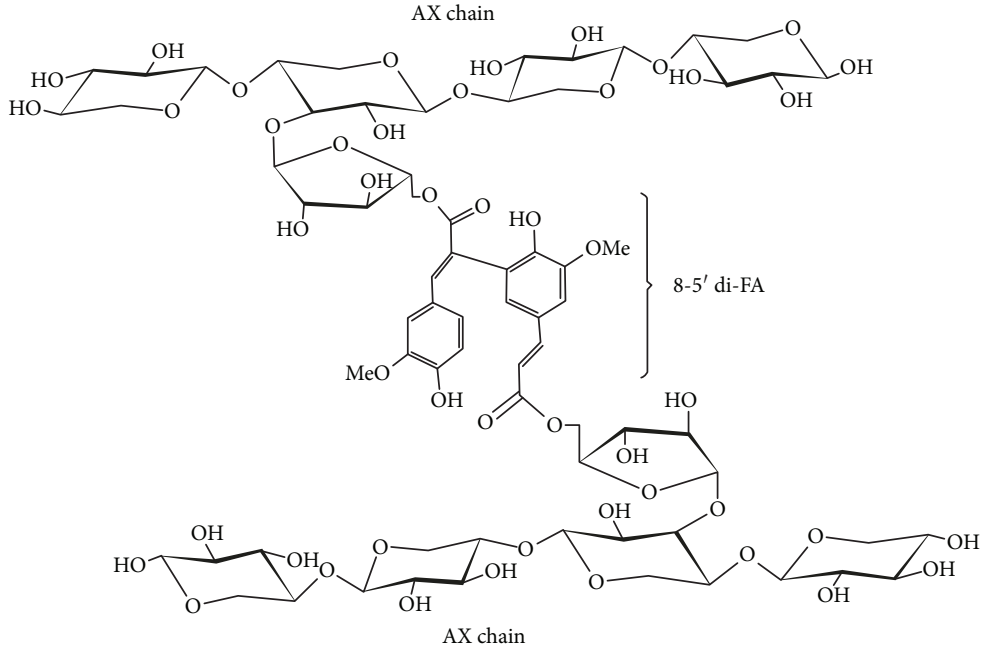

(b)

FIgURE 2: (a) Schematic representation of FA dimerization. (b) Covalent cross-linking of ferulated AX. Formation of 8-5' di-FA is presented as an example. AX: arabinoxylan; FA: ferulic acid; di-FA: ferulic acid dimer.

of MGN-3 or curcumin alone showed an inhibition of cell proliferation in a dose-dependent manner. The combination of MGN-3 and curcumin caused a synergistic effect characterized by a decrease in cell number and an increase in apoptotic cells. The expression of the proapoptotic protein (Bax) increased, while antiapoptotic protein (Bcl-2) decreased, which favored apoptosis. These findings indicated that Biobran and curcumin synergize in the induction of apoptosis [76]. A similar behavior was observed when Biobran was combined with paclitaxel in order to sensitize human and murine breast cancer cells (MCF-7 and 4T1) to paclitaxel. A synergistic effect between Biobran and paclitaxel resulted in damage of DNA, enhancement of apoptosis, and inhibition of $4 \mathrm{~T} 1$ cell proliferation [77].

In sum, researches have demonstrated the anticancer potential of the AX. Such property is attributed to both the antioxidant and prebiotic capacity of the polysaccharide. In addition, it is suggested that AX exerts its anticancer effect by a mechanism which involves its immune-modulation ability. In vitro as well as in vivo studies have evidenced the anticancer effect of AX on different types of cancer. Nevertheless, most studies highlight its beneficial effects in the prevention of colon cancer, due to the benefits of its prebiotic activity and immunostimulatory activity.

2.3.4. Gelling. A particular property of AX is their capacity to form covalent hydrogels. AX can gel through the covalent cross-linking of FA [6], under the action of different chemical (ferric chloride, ammonium persulphate) or enzymatic (laccase $/ \mathrm{O}_{2}$, peroxidase $/ \mathrm{H}_{2} \mathrm{O}_{2}$, linoleic acid/lipoxygenase) oxidizing agents [78-83] (Figure 2(b)). The ability of AX to gel depends on the concentration of the polysaccharide, Mw, and particularly the FA content [27].
The oxidative gelation of AX results from the dimerization of FA residues of adjacent polysaccharide chains leading to the formation of the three-dimensional network where the aqueous phase is retained. The FA dimerization mechanism occurs as follows: first, an oxidizing agent attacks the $\mathrm{H}$ atom of the $\mathrm{OH}$ group at the ring position of FA resulting in a phenoxy radical. Then, this radical is stabilized by resonance and located at three different positions onto the whole molecule, two on the aromatic ring (C-4 and C-5) and one at the double bound (C-8) of its side chain. In the next step, the crosslinking between two phenoxy radicals is carried out; the coupling of unpaired electrons of two different radicals forms a covalent linkage which connects the two polysaccharide chains. Thus, the structure of the dimers formed during gelation will depend on the radical position [48] (Figure 2(a)).

During gelling, the coupling of FA results in different structures. In AX gels, five di-FA, 8-5', 8-O- $4^{\prime}, 5-5^{\prime}, 8-5^{\prime}$ benzo, and $8-8^{\prime}$, have been detected, with $8-5^{\prime}$ and $8-\mathrm{O}-4^{\prime}$ being the most abundant [48], and one tri-FA $\left(4-\mathrm{O}-8^{\prime} / 5^{\prime}-5^{\prime}\right)$ [84]. In addition, the presence of noncovalent weak interactions (hydrogen bonds) may contribute to the stability of the gel $[85,86]$.

During the formation of the AX gel, the FA is oxidized and disappears as a result of the formation of cross-links (di-FA and tri-FA). Nevertheless, the concentrations of di-FA and tri-FA formed at the end of gelation do not compensate for the decrease in the FA monomers. Therefore, the formation of superior FA oligomers (FA tetramers, FA pentamers) have been proposed by several authors $[84,86]$. In the cell wall of cereals, five tri-FA, $5-5^{\prime} / 8-\mathrm{O}-4^{\prime}$, $8-\mathrm{O}-4 / 8-\mathrm{O}-4^{\prime}, 8-8^{\prime}$ (cyclic) $/ 8-\mathrm{O}-4^{\prime}, 8-\mathrm{O}-4^{\prime} / 8-5^{\prime}$ (noncyclic), 5$5 / 8-\mathrm{O}-4^{\prime}\left(\mathrm{H}_{2} \mathrm{O}\right)$, and two FA tetramers, $4-\mathrm{O}-8^{\prime} / 5-5^{\prime} / 8-\mathrm{O}-4^{\prime}$ and $4-\mathrm{O}-8^{\prime} / 5-5^{\prime} / 8-5^{\prime}$, have been identified and characterized 
TABLE 2: In vivo studies on the evaluation of the prebiotic effect of AX.

\begin{tabular}{lc}
\hline Animal model & \multicolumn{1}{c}{ Diet/experimental time } \\
\hline Male chickens & $\begin{array}{r}\text { Control diet (CT), diet supplemented with } \\
\text { XOS, wheat bran-derived AXOS, whea } \\
\text { endosperm alkali-solubilized AX. 2 w }\end{array}$ \\
\hline Male C57bl6/J mice & $\begin{array}{c}\text { Control diet, high-fat (HF) diet, HF } \\
\text { diet supplemented with AX. 4 w }\end{array}$
\end{tabular}

diet supplemented with AX. $4 \mathrm{w}$

\begin{tabular}{cc} 
Findings & Reference \\
\hline All treatments increased bifidobacteria. & \\
AX decreased body weight gain after 2 & [89] \\
weeks of feeding compared with CT. & \\
\hline
\end{tabular}

HF diet supplemented with AX restored

microbiota with a major effect on Roseburia

spp., Bacteroides-Prevotella spp., and bifidobacteria.

Improvement of gut barrier function, decrease in adipocyte size, fatty acid uptake, fatty acid oxidation and inflammation, and decrease in key lipogenic enzyme activity in the subcutaneous adipose tissue.

LC-AX and IN increased SCFA levels (propionate and butyrate, resp.). Stimulation

Male germ-free Fisher 344 albino rats inoculated with human faecal microbiota
Control diet, diet supplemented with long-chain AX (LC-AX) and diet supplemented with inulin (IN). $6 \mathrm{w}$ of butyrate-producing bacteria and bifidobacteria, respectively. Reduction of mucin-degrading Akkermansia muciniphila and more mucin production by the host. Less weight gain.

WU-AX supplementation increased butyrate production and butyrate-producing bacteria.

WE-AX and/or AXOS reduced $\mathrm{pH}$, suppressed relevant markers of proteolytic breakdown, and induced selective bifidogenic response.

Male Wistar rats WE-AX, and AXOS. 14 days
Combination of WU-AX, WE-AX, and AXOS showed a synergic effect.
AXOS supplementation exerted a bifidogenic

effect. Improvement of the HF-induced body weight gain, fat mass development, hyperinsulinemia, insulin resistance, endotoxemia, and inflammatory disorders in a model of HF diet-induced obesity.
Male C57bl6/J mice

Pigs
Control diet, high-fat (HF) diet, $\mathrm{HF}$ diet supplemented with AXOS. $8 \mathrm{w}$

AXD feeding shifted the microbial composition
towards butyrogenic species in the faeces and
increased the large-intestinal butyrate pool size.

w: week.

[87]. The latest evidence suggests the possibility that the missing FA at the end of the gelling process could be related with the formation of superior structures that are not yet identified.

The AX gels present interesting features with a wide range of applications. These gels have neutral flavor, odor, and color as well as high water absorption and exhibit $\mathrm{pH}$, temperature, and ionic stability [7]. They usually form quickly, and they are strong and thermostable [88]. In addition, they acquire a meso- and macroporous structure and have a dietary fiber nature. Due to their interesting characteristics, AX gels could be good candidates for their use as controlled release matrices for bioactive agents in the pharmaceutical, cosmetic, and food industries [7].

As previously mentioned, the antioxidant and prebiotic properties depend on the structure of AX. The presence of phenolic acids in AX, particularly FA, has been related to its prebiotic as well as antioxidant capacities. In addition, the resulting products of the enzymatic hydrolysis of AX exert important prebiotic properties. Then, it can be possible that the cross-linking process and formation of superior ferulate structures may contribute to some extent to the antioxidant and prebiotic properties of AX gels.

2.4. Preclinical Studies. Several in vivo studies have been performed in order to explore the potential of $\mathrm{AX}$ to exert its prebiotic, antioxidant, and anticancer effects. Following, the characteristics and findings of some of the most recent studies evaluating the effects of AX administration on animal models (mainly rats and mice) are presented.

2.4.1. Prebiotic Effect. The prebiotic effect of AX and their derivatives, xylooligosaccharides (XOS) and AXOS, has been tested in vivo. Several studies using animal models (mainly rats) demonstrate the potential prebiotic effect of AX through different observations: showing a bifidogenic effect, modulation of mucosa and gut microbiota, and increasing SCFA levels (mainly propionic and butyric acid), among others. Table 2 shows the characteristics and observations of some studies performed during the last 10 years related to the evaluation of the prebiotic properties of AX. 
The supplementation of wheat AX to high-fat (HF) diet in mice led to an increase in bifidobacteria, particularly $B$. animalis lactis. In addition, AX modulated the microbiota by restoring the levels of bacteria (Bacteroides-Prevotella spp., Roseburia spp.) that were decreased with the HF. The bifidogenic effect of AX was correlated with lower levels of inflammatory markers in the serum which resulted in the improvement of the gut barrier functions. The consumption of AX also decreased body weight gain and fat mass development in the HF diet-induced obesity group. Moreover, the hypercholesteremia and the content of free cholesterol in the liver decreased in HF diet feeding. The presence of smaller adipocytes in the group treated with HF diet and AX was also observed which was attributed to the ability of AX to decrease the expression of genes involved in adipocyte differentiation, fatty acid uptake and oxidation, lipolysis, and fatty acid synthesis. The authors proposed a positive correlation between the modulation of microbiota and the antiobesity action as well as the cholesterol-lowering effect observed in the experiment [39]. Similar effects were observed when diet-induced obese mice were fed with a HF diet supplemented with wheat-derived AXOS. A positive correlation between the increase of bifidobacteria and improvement of metabolic endotoxemia and inflammatory markers was also observed with administration of AXOS. A higher expression of the tight junction proteins Z01 and claudin 3 led to a better function of the gut barrier. Moreover, the peptides GLP-1 and PYY, which are involved in the regulation of food intake and glucose homeostasis, respectively, increased after AXOS supplementation. This increase could be related with lower food intake and the improvement of insulin sensitivity in mice [13].

The supplementation of long-chain AX (LC-AX) in rats inoculated with human faecal microbiota has been associated with the production of propionic acid and stimulation of $B$. longum. LC-AX administration also increased the production of mucin, while it shifted mucin degradation from the caecum to the colon. The degradation of mucin in the distal regions of colon could be beneficial as most chronic colonic diseases, such as ulcerative colitis and colorectal cancer, originate in this region [90].

2.4.2. Antioxidant Effect. The antioxidant property of AX has been related with several beneficial effects. In vivo studies, using rats, show that $\mathrm{AX}$ exerts its antioxidant effect by modulating lipid peroxidation, improving the activity of antioxidant enzymes, and protecting against oxidative stress. These positive effects have been related to the mechanisms of AX to exert its anticancer effect as well as improve lipid metabolic disorder and suppress lipid peroxidation.

Recently, male Sprague-Dawley fed with a HF diet supplemented with AX (HF-AX) showed lower triglyceride concentration in serum in comparison with the HF diet group. Higher lipoprotein lipase (LPL), hepatic lipase (HL), total lipase, and acyl-CoA oxidase (ACO) activities and lower triglyceride and cholesterol levels in the liver of the HF-AX group were observed. The authors suggest that intake of AX helped to alleviate lipid metabolic disorder by reducing triglycerides and low-density lipoprotein in serum of rats. The administration of HF-AX changed the lipid metabolism by improving the activity of fatty acid oxidation enzymes (LPL, HL, and ACO) which helped to reduce the triglyceride levels in liver. AX could help to maintain normal fat levels by activating lipid catabolism and oxidation rather than inhibiting lipid synthesis. Moreover, the activity of antioxidant enzymes glutathione peroxidase and total superoxide dismutase was also improved by the ingestion of AX resulting in a reduction of the oxidative stress in serum and tissues. The results also indicated that AX may alleviate the damage of hepatic morphology by regulation of liver cell apoptosis (Bax). These findings showed that supplementation of AX improved lipid metabolic disorder and alleviated liver damage by activation of liver lipid catabolism and suppression of lipid peroxidation in rats [92].

2.4.3. Anticancer Effect. AX and AXOS have been investigated in order to explore their anticancer effects. The anticancer property of these polysaccharides on different types of cancer such as colon cancer, glandular stomach cancer, neuroblastoma, and liver cancer, among others, has been tested in vivo. According to the observations of the research done in the last 10 years, it is proposed that AX and AXOS may exert its anticancer effect through different mechanisms involving antioxidant, prebiotic, and immunomodulatory properties (Table 3 ).

The inhibition of growth of tumors in S180 tumorbearing mice was significant when animals were administered with wheat bran AX. According to the results obtained in this study, it is suggested that AX exerts its antitumor activity via the improvement in immune response. The administration of $\mathrm{AX}$ enhanced the macrophage phagocytosis of chicken red blood cells (CRBCs) in tumor-bearing mice. The killing activity of NK cells from splenocytes in mice was increased, suggesting that AX could enhance the cytotoxic activity against spontaneously derived tumor cells. Moreover, AX treatment improved the production of IL-2 in blood serum of mice and subsequent proliferation of T cells, B cells, NK cells, and monocytes, increasing the cytotoxicity of $\mathrm{T}$ and NK cells. It is also proposed that the immunostimulating activity of AX may be related to the metabolism in vivo [16].

More recently, the chemopreventive activity of MGN-3/ Biobran on glandular chemical induction of stomach carcinogenesis in rats was evaluated. The Biobran administration ( $40 \mathrm{mg} / \mathrm{kg}$ weight, 8 months) showed a significant reduction in the incidence of animals bearing dysplasia and adenocarcinoma. In addition, Biobran induced cancer cell apoptosis via cell cycle arrest of gastric cancer cells in the sub-G1 phase and also via the mitochondria-dependent pathway as indicated by upregulation of p53, Bax expression, downregulation of $\mathrm{Blc}-2$, and an increase in $\mathrm{Bax} / \mathrm{Bcl}-2$ ratio. The authors suggest that the immunomodulatory effects of Biobran may represent another mechanism by which this agent suppresses the growth of adenocarcinoma [15].

\subsection{Mechanisms Underlying the Anticancer and Antioxidant Effects of $A X$}

2.5.1. Immune-Modulation. In the last years, research efforts have focused on elucidating the mechanisms by which AX 
TABLE 3: Description of studies evaluating the anticancer potential of $\mathrm{AX}$ and AXOS, in vivo.

\begin{tabular}{lccc}
\hline $\begin{array}{l}\text { Type of cancer/animal } \\
\text { model }\end{array}$ & $\begin{array}{c}\text { Carcinogenic agent/ } \\
\text { cancer cells }\end{array}$ & Dosage/experimental time & Findings \\
\hline
\end{tabular}

\begin{tabular}{lcc}
\hline & & \\
& & MGN-3/Biobran \\
& & $(25 \mathrm{mg} / \mathrm{kg}$ bw $)$ ip \\
Solid Erlich & Erlich ascites, carcinoma & Six times/week for 25 \\
carcinoma & cells, and intramuscular & days at either day 4 or \\
Female albino mice & inoculation & day 11 post-cancer cell \\
& & inoculation.
\end{tabular}

MGN-3 suppressed the growth of tumors, normalized lipid peroxidation, and increased glutathione contents. Increased activity of endogenous antioxidant scavenging enzymes (superoxide dismutase, glutathione peroxidase, catalase, and glutathioneS-transferase) in blood, liver, and tumor tissue.

\begin{tabular}{lcc}
\hline & & High-fat diet plus \\
Colon carcinogenesis & 1,2,-Dimethylhydrazine & AXOS (48 g/kg). \\
Male F344 rats & (DMH), subcutaneous & 10 days before receiving \\
injection. & carcinogen and continued \\
& & for 13 weeks.
\end{tabular}

Lower counts of preneoplastic lesions (mucin depleted foci (MDF)) in comparison to the control group. Fewer preneoplastic lesions (aberrant crypt foci (ACF)) in the distal part of the colon.

\begin{tabular}{lcc}
\hline & & \\
S180 tumor-bearing & Mouse sarcoma S180 & AX orally administered \\
mice & cells, intramuscular & $(100,200$, and \\
ICR male mice & inoculation. & $400 \mathrm{mg} / \mathrm{kg} \mathrm{bw})$.
\end{tabular}

\section{Administration of AX significantly} inhibited the growth of mouse transplantable tumors and promoted thymus and spleen indexes, splenocyte proliferation, NK cell and macrophage phagocytosis activity, and IL-2 production. Increased peripheral leukocyte count and bone marrow cellularity.

\begin{tabular}{lc}
\hline & \\
Neuroblastoma & Injection of NB1691luc \\
NOD-scid & cells. \\
IL-2Rgnull mice &
\end{tabular}

\section{NK cells activated with \\ $100 \mu \mathrm{g} / \mathrm{mL}$ MGN-3/}

Biobran injected intravenously.

7 days after injection of tumor cells and performed twice a week for 4 weeks.
Significant inhibition of neuroblastoma growth and improvement in survival in the group treated with Biobran. Increase in the activation-associated receptors CD69 and CD25 on NK cells.

Biobran reduced incidence of animals bearing gastric dysplasia and adenocarcinoma.

MNNG plus Biobran

Glandular stomach carcinogenesis. Male Wistar rats
(40 mg/kg bw) every other day via oral gavage. 8 months
Decrease in expression of tumor marker

$\mathrm{Ki}-67$ and increase in the level of apoptotic gastric cancer cells via cell cycle arrest

(sub-G1) and mitochondria-dependent pathway. Protection against lymphocytopenia.

\begin{tabular}{|c|c|c|c|c|}
\hline & & & & \\
\hline $\begin{array}{l}\text { Hepatocarcinogenesis. } \\
\text { Male albino rats }\end{array}$ & $\begin{array}{l}\text { N-nitrosodiethylamine } \\
\text { (NDEA) and carbon } \\
\text { tetrachloride }\left(\mathrm{CCl}_{4}\right) \text {. }\end{array}$ & $\begin{array}{c}\text { MGN-3/Biobran } \\
(25 \mathrm{mg} / \mathrm{kg} \text { bw }), \\
5 \text { times/week ip } \\
2 \text { weeks prior to } \\
\text { receiving carcinogen and } \\
\text { continued for } 20 \text { weeks. }\end{array}$ & $\begin{array}{c}\text { Reduction in liver tumor incidence, } \\
\text { decrease of preneoplastic foci in hepatic } \\
\text { parenchyma, and inhibition of development } \\
\text { of hepatocellular carcinoma. Regulation } \\
\text { of AST, ALT, ALP, and gamma GT levels. } \\
\text { Increase in cell cycle sub-G0/G1 population. } \\
\text { Downregulation of expression of NF- } \kappa \text { Bp65 and } \\
\text { Bcl } 2 \text {, upregulated p53, Bax, and caspase- } \\
3 \text { and increased the Bax/Bcl-2 ratio. }\end{array}$ & [94] \\
\hline
\end{tabular}

bw: body weight; ip: intraperitoneal; AST: serum aspartate aminotransferase; ALT: alanine aminotransferase; ALP: alkaline phosphatase; gamma GT: gamma glutamyl transpeptidase.

exerts its anticancer effects. In this regard, several studies have demonstrated that one of such mechanisms could involve the immune-modulation properties of AX.

It has been proposed that MGN-3/Biobran (AX from rice) exhibits its anticancer effects due to its ability to act as a biological response modifier (BRM). BRM are designed to activate the host immune response to destroy cancer cells
[41]. Thus, Biobran has demonstrated to improve the activities of different arms of the immune system to attack cancer cells (Figure 3). Biobran improves the reactivity of cells with anticancer activity such as NK cells and CD8+ T cells and modulates the production of certain cytokines such as interferon-gamma (IFN- $\gamma$ ), -lambda (IFN- $\lambda$ ), IL-2, and IL12 [41]. The basis of the mechanism behind the immune 


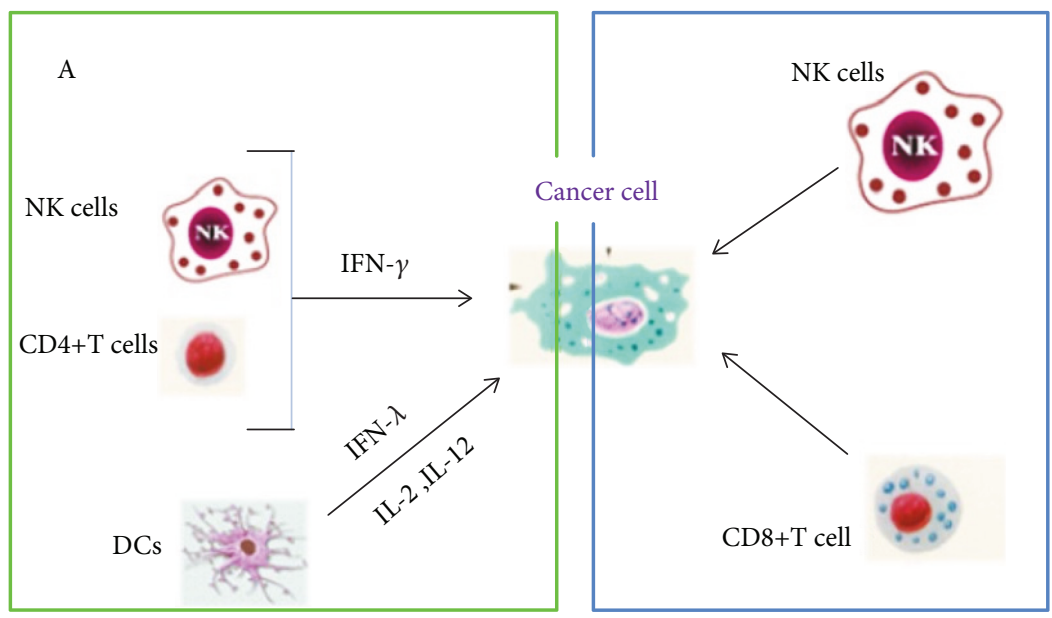

FIGURE 3: MGN-3/Biobran enhances the cytotoxicity reactivity of immune cells with anticancer effect and the production of certain cytokines (adapted from [41]).

modulatory effects of Biobran is not completely elucidated. However, it is proposed that these AX are hydrolyzed in order to reduce its MW so they can diffuse through intestinal walls or directly into the blood stream and then be transported to the lymph nodes where immune cells reside $[95,96]$.

NK cells play an important role in the natural defense of the immune system against cancer and viral infections [93]. These cells work by attaching to cancer cells and releasing their granules which form holes causing cell death [41]. AX has the ability to increase the cytotoxicity activity of NK cells as confirmed by several in vitro and in vivo studies $[16,93]$. Dendritic cells (DCs) are important antigenpresenting cells (APCs) involved in generating antitumor immune response. Biobran upregulates CD80 and CD86 which are molecules expressed on mature DCs. This stimulation promotes the production of proinflammatory and immune-regulatory cytokines. It is proposed that Biobran could bind to the cell surface receptors (TLRs and/or C type lectins) or to intracellular receptors (NLRP3 inflammasome) and trigger signaling pathways involved in cell activation and cytokine production [41].

A recent study evaluated the potential capacity of Biobran to activate and improve the cytotoxicity of NK cell activity against neuroblastoma in vitro, using several pediatric cell lines (acute leukaemia, neuroblastoma, Ewig sarcoma, embryonic rhabdomyosarcoma, and alveolar rhabdomyosarcoma) and in vivo (NOD/scid/IL-2R $\gamma$ null neuroblastoma model) [93]. The stimulation of NK cells with Biobran resulted in a higher expression of the activation-associated receptors CD25 and CD69 than in unstimulated cells. In addition, the stimulation increased NK cell cytotoxicity against cancer cell lines and reduced the neuroblastoma growth in vivo. Several mechanisms are proposed in order to explain how Biobran could stimulate NK cell activity. One of those theories establishes an apoptotic effect mediated by the activation of NK cells releasing TNF- $\alpha$ and IFN- $\gamma$ [75]. Other mechanisms could be related with the increasing of activating receptors on Biobranstimulated NK cells. The authors observed an increase in the activation-associated receptor CD69 and CD25 on stimulated NK cells. The increase of CD69 is associated with a higher cytotoxicity of NK cells, while CD25 expression on NK cells is indicative of proliferation potential $[97,98]$. NK cells attack cancer and viral cells through the release of their granules that cause cell death. In this regard, Biobran treatment increases the granular content (perforin and granzyme) of NK cells favoring its activity against malignant cells [99]. In addition, the treatment with Biobran helps NK cells to attach cancer cells [41].

AX can stimulate the production of interleukins such as cytokines IL-2 and IL-12 which are the main anticancer cytokines in humans [41]. In S180 tumor-bearing mice, the treatment with AX led to an increase in the secretion of IL-2 in the blood of mice. It is postulated that increase of IL- 2 may be a mechanism for AX to exert antitumor effects, as IL-2 can improve the proliferation of T cells, B cells, NK cells, and monocytes and increase the cytotoxicity of T cells and NK cells $[16,100]$. In addition, the ingestion of Biobran increased the production of IL-12 in multiple myeloma patients at one and two months post-ingestion [101].

AX can induce the production of TNFs (IFN- $\lambda$ and IFN- $\gamma$ ) which have been found to exhibit antitumor activity $[75,101,102]$. In a previous study, the oral administration of partially hydrolyzed AX from corn husk to mice increased the production of IL- 2 and IFN- $\gamma$ and slightly increased IL-4 in mitogen-induced proliferation spleen cells. In addition, an increase in the activity of NK cells in spleen cells from transplanted-tumor mice was observed [102]. T helper 1 (Th1) promotes antitumor immunity through the production of IL- 2 and IFN- $\gamma$, which activates NK cells to attack cancer and virus-infected cells [103]. In this study, the administration of AX also decreased ear inflammation of a model mouse of atopic dermatitis. According to the results obtained, it is suggested that the anti-inflammatory effect of AX is attributed to the activation of an IFN- $\gamma$-dependent Th1-like immune response in mice. In another study, multiple myeloma patients presented an increase of IFN- $\gamma$ at two months post-treatment with MGN-3 [101].

$\mathrm{T}$ regulatory lymphocytes ( $\mathrm{T}$ reg) or CD4+CD25+ lymphocytes act by suppressing the antitumor cytotoxic immune response [104]. In this regard, it is proposed that the counteracting of $\mathrm{T}$ reg cell activity could interfere in a positive way 
with the progression of neoplastic diseases by improving the efficacy of the anticancer immune response [41]. AX from rice was given orally to 22 patients with solid tumor for two months. The results showed an increase in $\mathrm{TH}$ cells, while $T$ reg cells decreased, but the differences were not statistically significant. On the contrary, the $\mathrm{TH} / \mathrm{T}$ reg ratio significantly enhanced after AX therapy [40].

2.5.2. Induction of Apoptosis. Induction of apoptosis appears to be another mechanism by which MGN-3/Biobran may exert its anticancer effects. In vivo studies evaluated the effect of Biobran on mice bearing a SEC tumor as well as in chemically induced glandular stomach adenocarcinoma rats. According to the results observed in those experiments, the anticancer activity exhibited by Biobran was explained through a mechanism via induction of apoptosis.

The administration of Biobran in mice bearing a SEC tumor caused a significant delay in the volume and weight of the tumor in comparison to the control. The authors proposed that the antitumor activity of Biobran was related to its ability to induce apoptosis and immune modulation. The intraperitoneal treatment of Biobran on mice increased the number of apoptotic SEC cells. Moreover, cytokine production was influenced by increasing the levels of tumor necrosis factor- $\alpha$ and IFN- $\gamma$, while a downregulation of the immune suppressing cytokine IL-10 was observed. In addition, a considerable increase in NK cell activity was observed in mice treated with Biobran [75]. Biobran can cause tumor regression by the induction of cancer cell apoptosis via its immunumodulatory effects on NK cells and cytokine production. It is known that NK cells kill cancer cells by different pathways, and one of those involves the ligation of FasL to its Fas receptor to induce apoptosis [105]. It is also possible that Biobran could exert its apoptotic effect via the increase of TNF- $\alpha$ and IFN- $\gamma$. In this regard, both TNF- $\alpha$ and IFN- $\gamma$ have been shown to act synergistically to induce cancer cell death through apoptotic and necrotic effects $[106,107]$.

Recently, the chemopreventive activity of Biobran against chemical induction of glandular stomach carcinogenesis in rats was associated with the ability of Biobran to induce apoptosis via the mitochondrial-dependent pathway in gastric cancer cells [15]. Biobran treatment caused a significant reduction in the incidence of animals bearing gastric dysplasia and adenocarcinoma in comparison to the untreated group. The upregulation in p53 expression, Bax expression, downregulation in Bcl-2 expression, the increase in Bax/ Blc-2 ratio, and the activation of caspase- 3 as well as the induction of cell-cycle arrest in the sub-G1 phase may explain the mitochondria-dependent pathway as the mechanism involved in the anticancer effect observed in the present study. Changes in p53, Bax, and Bcl-2 can alter the outer mitochondrial membrane and subsequent release of cytochrome $\mathrm{C}$, which finally activates caspase-3. In this regard, Biobran has shown to induce apoptosis via activation of caspase-8, -9 , and -3 [108]. Although the mechanism by which Biobran exerts its apoptotic effect is not completely elucidated, it could be related to the capacity of Biobran to sensitize the surface CD95 receptor that is involved in the triggering of apoptosis [109]. On the other hand, another possible mechanism by which Biobran suppresses the growth of tumor could be related to its immunomodulatory properties. It was observed that treatment with Biobran protected against chemical-induced lymphocytopenia in rats. Lymphocytes are white blood cells which are part of the immune system [15].

2.5.3. Antioxidant. AX has been found to exert antioxidant effects through the modulation of lipid peroxidation, promoting the antioxidant defense system and protecting against oxidative stress [19]. Although the mechanisms behind the antioxidant property of AX are not fully understood, some studies suggest that its capacity to increase the activity of endogenous antioxidant enzymes, suppress lipid peroxidation, and induce apoptosis could be involved in such mechanisms $[19,92]$. The antioxidant activity of AX has been related to its capacity to exert anticancer effect, improve lipid metabolic disorder, and alleviate liver damage in rats.

Noaman et al. [19] evaluated the antioxidant activity as a possible mechanism of Biobran to exert its antitumor potential on mice inoculated with Erlich ascites carcinoma (EAC) cells. Biobran administration suppressed tumor growth by normalizing the lipid peroxidation level and augmentation of glutathione (GSH) contents. In addition, the expression and activity of endogenous antioxidant scavenging enzymes (superoxide dismutase, glutathione peroxidase, catalase, and glutathione-S-transferase) in the cells of normal and tumorbearing animals were increased in blood, liver, and tumor tissue. The ability of Biobran to induce apoptosis was proposed as the mechanism by which it could exert those antioxidant effects. Reactive oxygen species (ROS) act as signaling molecules for the initiation and execution of apoptosis. GSH and thioredoxin not only regulate ROS levels but could act as reversible redox modifiers of enzyme function [110]. In this regard, higher levels of GSH content in tissues of mice treated with Biobran were observed in comparison to the untreated mice. Among other functions, glutathione-Stransferase enzymes detoxify carcinogens [111]. This also could be a possible mechanism for Biobran to prevent cancer as elevated levels of such enzymes were observed in mice treated with Biobran.

The antioxidant capacity of AX has been also related to the improvement of metabolic disorder and alleviate liver damage in rats induced by high-fat diet [92]. Lipid peroxidation is one of the most common free radical chain reactions that causes oxidative damage [112]. In this study, mice fed with a high-fat diet presented an increase in serum and tissue oxidative stress and subsequent reduction of the antioxidant enzymes glutathione peroxidase and total superoxide dismutase as well as an increase in malondialdehyde level. On the contrary, supplementation of AX in high-fat diet catalyzed the dismutation of the superoxide $\left(\mathrm{O}_{-2}\right)$ radical into either molecular oxygen $\left(\mathrm{O}_{2}\right)$ or hydrogen peroxide $\left(\mathrm{H}_{2} \mathrm{O}_{2}\right)$ by the promotion of total superoxide dismutase. In addition, the increase in glutathione peroxidase activity reduced lipid hydroperoxides [92]. On the other hand, AX supplementation could alleviate damage liver morphology by regulating the liver cell apoptosis through the modulation of the expression of proapoptotic and antiapoptotic proteins, Bax and Bcl- 

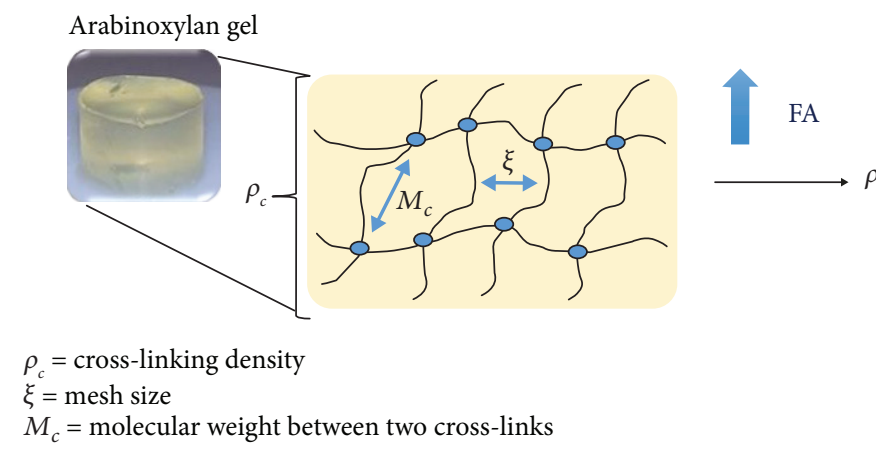

More compact structure of the gel

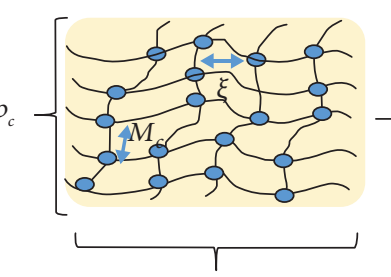

(i) Higher $\rho$

(ii) Smaller $\xi$

(iii) Smaller $M_{c}$
Matrices for controlled release of biomolecules

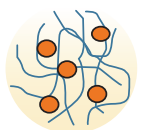
Improvement of encapsulation and release in the target site

Figure 4: Structural parameters of ferulated AX gels.

2. Moreover, Biobran has the ability to change the lipid metabolism by regulating the expression of UCP2, a mitochondrial membrane protein that works by accelerating the fatty acid $\beta$-oxidation and minimizing the production of reactive oxygen species [113]. These results may suggest that Biobran improved lipid catabolism and protected liver damage via an antioxidant mechanism.

\section{Arabinoxylan Gels}

3.1. Structural Parameters. The structural characteristics of the AX gels can be measured as a function of the determination of different parameters. The cross-linking density $\left(\rho_{c}\right)$, the mesh size $(\xi)$, and the molecular weight between crosslinks $\left(M_{c}\right)$ can be calculated by the determination of the swelling ratio of the gels [84] (Figure 4). These parameters allow to elucidate how the cross-linking between the AX chains could occur during the gel formation. Therefore, the knowledge of such structural characteristics is determinant to understand the gel properties and thus their possible applications.

The content of FA in $\mathrm{AX}$ is an important factor affecting the gel structure. Table 4 shows the structural parameters and the FA content of maize and wheat AX gels at $2 \%(w / v)$. Usually, the increase in the FA content results in a decrease in mesh size and the molecular weight between cross-links, as well as an increase in the cross-linking density. This behavior results in the formation of gels with a more compact structure $[9,25,84]$ (Figure 4). Gels with a compact structure are suitable for potential applications in the controlled release of biomolecules because they provide a better encapsulation and ensure the release of biomolecules in the site of interest.

The swelling ratio $(q)$ indicates the amount of water that can be absorbed by the gel inside its tridimensional network. Martínez-López et al. [9] observed that when the AX concentration increased from 4 to $6 \%(w / v)$ in the gel, the $q$ value decreased from 18 to $9 \mathrm{~g}$ water/g AX. Similar results have been reported by other authors $[33,84]$. The results are explained in terms of a higher concentration of AX in the gel, which involves a high amount of FA, and it is related with a more compact polymeric structure that limits the water absorption capacity. In contrast, gels with lower polymer concentrations present higher $q$ values due to a decrease in the covalent cross-links (di-FA and tri-FA). This decrease is attributed to longer uncross-linked chain sections in the gel,
TABLE 4: Structural parameters of AX gels at 2\% $(w / v)$.

\begin{tabular}{lccc}
\hline Origin of AX & $\begin{array}{c}M_{\mathrm{c}} \times 10^{3} \\
(\mathrm{~g} / \mathrm{mol})\end{array}$ & $\xi(\mathrm{nm})$ & $\begin{array}{c}\rho_{c} \times 10^{-6} \\
\left(\mathrm{~mol} / \mathrm{cm}^{3}\right)\end{array}$ \\
\hline Wheat $(2 \mu \mathrm{g} \mathrm{AF} / \mathrm{mg} \mathrm{AX})^{\mathrm{a}}$ & 119 & 201 & 14 \\
Maize $(6 \mu \mathrm{g} \mathrm{AF} / \mathrm{mg} \mathrm{AX})^{\mathrm{b}}$ & 34 & 96 & 67 \\
\hline
\end{tabular}

${ }^{\mathrm{a}}[85] \cdot{ }^{\mathrm{b}}[25]$.

which facilitate its expansion, leading to high water absorption $[114,115]$.

The knowledge of the structural characteristics of the gel allows proposing different applications according to its functional properties. In this sense, we can take advantage about the quite relationship between the polysaccharide characteristics and the structural parameters of the gel $\left(\xi, M_{c}\right.$, and $\left.\rho_{c}\right)$. This information can help to predict the gel structure and thus consider it for specific applications.

3.2. Microstructure. The microstructure of the AX gels has been studied by different microscopy techniques, with scanning electron microscopy (SEM) being the most used. The SEM micrographs have permitted a thorough understanding about the network of the AX gels. Several reports agree that lyophilized AX gels exhibit an imperfect honeycomb-like structure (Figure 5) $[25,35,116]$. This structure is mainly attributed to the polysaccharide characteristics. Although such structure could be established as a pattern for the gel networks, certain factors such as the molecule characteristics, structural parameters of the gel, or even the methods used prior to the analyses could affect the microstructure of these gels.

AX gels are characterized for presenting a porous and heterogeneous structure. However, depending on the polysaccharide characteristics, gels with different morphologies can be obtained. In SEM images, Martínez-López et al. [117] observed that maize bran AX gels showed an irregular honeycomb structure, while the nejayote AX gels appeared as a mix of sheets and rigid plates. The method used for freezing prior to the freeze drying process is another important factor affecting the gel microstructure. A rapid freezing (nitrogen immersion) of the gel results in the formation of smaller pores, compared to those obtained when using a slow freezing method $[116,118]$. The freezing rate affects the quality of the frozen material, particularly those containing high 


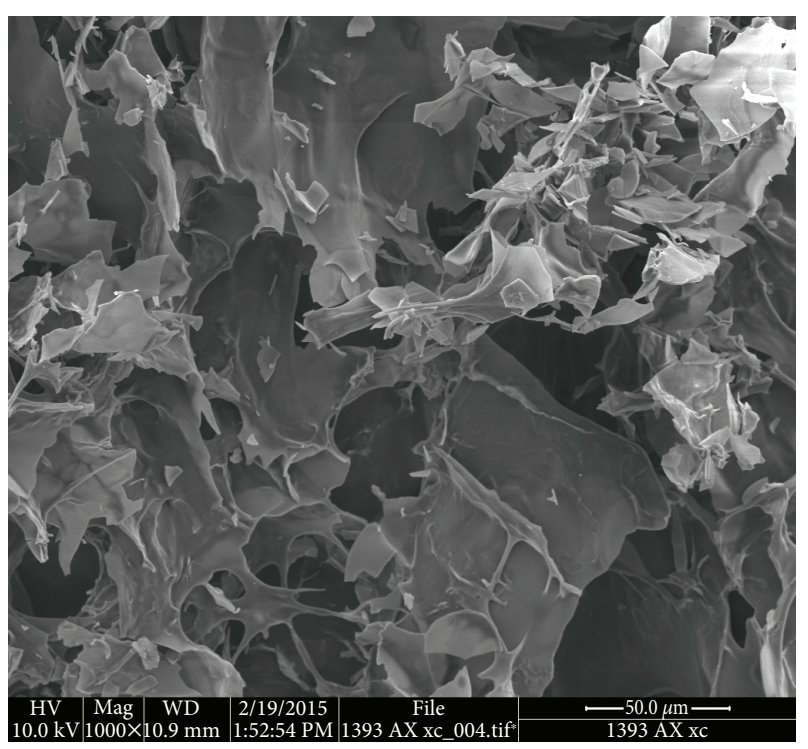

FIGURE 5: SEM image of the microstructure of lyophilized AX gel from maize at $1000 \mathrm{x}$.

amounts of water such as gels [118]. Therefore, a fast freezing results in a better-preserved structure of the gels.

Martínez-López et al. [119] evaluated the microstructure of AX microspheres by SEM. The microsphere's morphology presented a heterogeneous network, with irregular pore sizes and geometries, similar to those reported for other micro gels. In addition, the authors reported the presence of clusters of interconnected nodular structures. These clusters resulted in the formation of small pores $(10-70 \mathrm{~nm})$, while the binding between clusters led to a macroporous structure. The authors explain that the pore size of the gels formed via phenolic acid cross-linking is determined by the presence of nodular conglomerates.

The microstructural analysis of the gel provides a thorough understanding about the morphological characteristics of this material. Among other aspects, this analysis permits to study the conformation of the gel obtained as a result of the interactions between the polysaccharide chains. In this regard, the knowledge of the microstructural characteristics of the gel allows establishing a relationship between the morphology of the gel and its functional properties.

3.3. Viscoelastic Characteristics. The viscoelastic characteristics of AX can be studied by small-amplitude shear oscillatory rheology. The rheological analysis allows identifying the nature of a viscoelastic material, as well as the rheological behavior of the gel formed. The gelation ability of AX depends on the concentration of the polysaccharide, the $\mathrm{Mw}$, the substitution degree, and particularly, the content of FA $[26,48]$.

The AX gels present a typical kinetic of a solid-like material. The kinetic of gelation of AX exhibits a rapid increase in the elastic modulus $\left(G^{\prime}\right)$, followed by a stability region, known as plateau [26] (Figure 6(a)). This behavior is due to the formation of covalent cross-links between the FA residues of the AX chains. The formation of cross-links in sufficient quantity limits the movement of the polysaccharide chains and leads to the formation of new cross-links. On the other hand, the mechanical spectrum for AX shows a behavior of a typical solid-like material with a linear $G^{\prime}$-independent of time and a $G^{\prime \prime}$ much smaller than $G^{\prime}$ and dependent of time [25, 84, 117] (Figure 6(b)).

Higher contents of FA result in the formation of stronger gels. Méndez-Encinas et al. [25] obtained stronger AX gels $\left(G^{\prime}=687 \mathrm{~Pa}\right)$ than Carvajal-Millan et al. [85] $\left(G^{\prime}=44 \mathrm{~Pa}\right)$, with a FA content of 6.05 and $2.3 \mu \mathrm{g} / \mathrm{mg} \mathrm{AX}$, respectively, and using similar polysaccharide concentrations. The latter shows the impact of the FA content on the rheological properties of the gels.

\subsection{Functional Properties}

3.4.1. Encapsulating. One of the most interesting properties of AX gels is their ability to encapsulate different agents. Several knowledge areas, such as the pharmaceutical, food, and medical, have special interest in investigating the encapsulating capacity of these gels. The research done on this respect ranges from the encapsulation of biomolecules and pharmaceuticals to cells (yeast and bacteria) $[33,37,85,86,120]$. The results have been quite promising, which has led to further research in this area.

In previous studies, Vansteenkiste et al. [86] evaluated the entrapment of a model protein (bovine serum albumin (BSA)) in AX gels and their protective effect against pepsin proteolysis and heating. The results indicated that the AX gel protected the embedded protein against enzymatic hydrolysis and also protected against heat.

Carvajal-Millan et al. [85] studied the capacity of AX gels with different FA contents to load model proteins. The results showed that the total protein loaded in the AX gels decreased as the concentration of AX in the gel increased. The authors proposed this decrease was due to the presence of a more compact network resulting from higher ferulate cross-linking structures, which turn down the protein movement within the gel. These results indicate that the structural characteristics of the gel affect its loading capacity, which in turn could also be true to proteins, other biomolecules, and even cells.

Regarding the medicine field, the search for, and the development of, novel encapsulating agents for the entrapment of probiotics has been of growing interest. MoralesOrtega et al. [37] evaluated the entrapment of bacteria (B. longum and B. adolescentis) in AX gels. The study showed the bacterial cells entrapped inside the network of the AX gel, suggesting that AX gels can be potential candidates for use in the entrapment of probiotics and even other cells of interest.

The encapsulation of small molecules such as methyl xanthine (caffeine) has also been investigated, with excellent results. Iravani et al. [35] encapsulated caffeine in AX gels. In addition, these gels were subjected to acidic conditions $(\mathrm{HCl}$ $0.1 \mathrm{M}$ ) in order to simulate the gastrointestinal fluid. AX gels are stable to acidic conditions due to its dietary fiber nature. Therefore, they have been a focus of study for their application as colon-targeted controlled-release systems. 


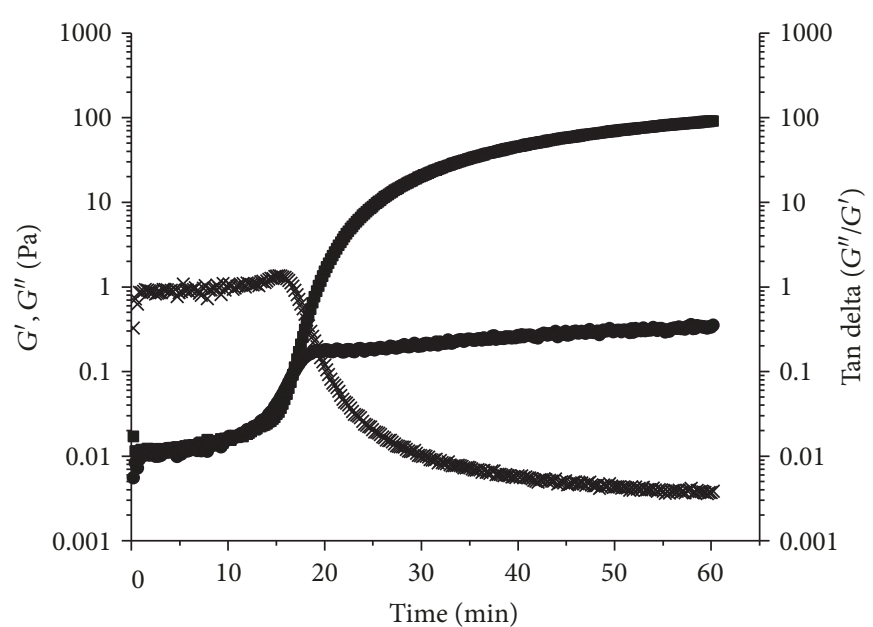

(a)

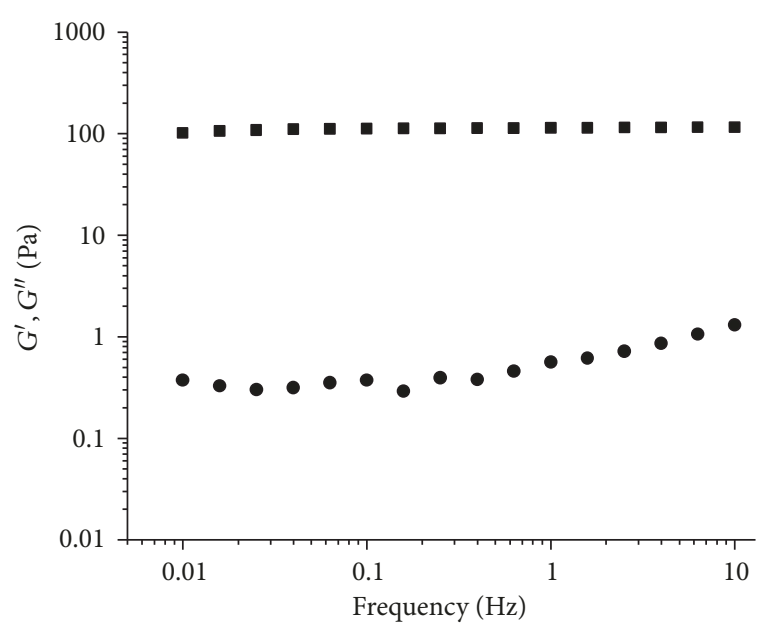

(b)

Figure 6: (a) Kinetic of gelation of AX solution $(2 \% w / v)$ at $0.25 \mathrm{~Hz}$ and $5 \%$ strain $\left(G^{\prime} \mathbf{\square}, G^{\prime \prime} \bullet, \tan \delta \mathrm{X}\right)$ and (b) mechanical spectrum of the AX gel formed, registered at $5 \%$ strain $\left(G^{\prime} \mathbf{\square}, G^{\prime \prime} \bullet\right)$.

3.4.2. Colon-Targeted Drug Delivery Systems. Polysaccharidebased matrices have been widely studied for their use as colon-targeted drug delivery systems. Most of the time, the use of a single polysaccharide does not permit a targeted release, so it is common to use the combining and modifying of polysaccharides. The variations in the $\mathrm{pH}$ and transit time in the gastrointestinal tract result in a premature or even absent drug release [24]. AX can form covalent gels, which are stable to temperature [88], $\mathrm{pH}$, and ionic strength changes [7]. Thus, AX gels have been considered as excellent candidates for their potential application in colon-targeted drug delivery systems.

AX gels have shown ability for use in controlled release of biomolecules, as well as cells (Table 5) [33, 35, 36, 85]. Previous studies evaluated the controlled-release properties of AX gels using model proteins such as ovalbumin, $\beta$-lactoglobulin, and insulin $[33,36]$. The study of Berlanga-Reyes et al. [33] showed that only $11-18 \%$ of the proteins (insulin and $\beta$-lactoglobulin, resp.) was released by the end of a $15 \mathrm{~h}$ in vitro test. The authors suggest that AX gels could be used as a carrier to protect the proteins from the gastric environment and assure their release at the colonic region where $\mathrm{AX}$ gels can be fermented by the microbiota.

Polysaccharide hydrogels are a good alternative for the protection and controlled release of proteins and peptides in the colon. These systems protect biomolecules from protease degradation in the gastrointestinal tract and assure its release in the target site. Chitosan and alginate are the most studied polysaccharides for the controlled release of molecules. Although chitosan has been widely used in drug delivery, its solubility in acidic conditions $(<\mathrm{pH} 6.0)$ limits its application in the intestinal tract $(>\mathrm{pH} 6.5)$ due to the early degradation and release of the molecule [122]. Covalent $\mathrm{AX}$ gels resist changes in $\mathrm{pH}$ [27], allowing their stability in the acidic conditions of the stomach and subsequent degradation in the colonic region by the microbiota [32].
Paz-Samaniego et al. [32] designed core-shell AX particles for the entrapment of insulin and probiotics (Bifidobacterium). The authors evaluated the degradation and release using a simulator of the gastrointestinal tract (Simgi). The encapsulation efficiency was 72 and $90 \%$ for insulin and probiotic, respectively. The results showed that only $24 \%$ of the insulin was lost before the particles reach the colon, while $76 \%$ of the protein was released in the colon region, mainly in the transverse section. In addition, an increase in the Bifidobacterium population was observed due to the fermentation of the particles by these bacteria in the colonic region. This study suggests that AX particles could be excellent candidates for the controlled release of insulin and probiotics in the colonic region as an alternative for the treatment of diabetes. A low percentage of insulin release (33\%) has been reported for insulin-loaded chitosan gel nanoparticles in pH6.8 phosphate buffer solution (intestinal conditions). Moreover, in vivo studies showed a low hypoglycemic effect in diabetes-induced rats administered with the nanoparticles indicating the poor drug release in the colon. These results were attributed to the insolubility of chitosan in neutral and alkaline media, affecting the degradation and subsequent release of insulin in the colonic region. Concerning the encapsulation efficiency, the authors reported an efficiency of $84 \%$ which was a higher value in comparison to that observed in the AX microspheres [32, 122]. These differences could be related to the electrostatic charges between insulin and chitosan which favored its association.

Calcium alginate gels are also widely used for the controlled release of biomolecules. Insulin-loaded alginate microspheres present good encapsulation efficiency from 65 to $79 \%$ [123] which is similar to that reported in AX particles (72\%) [32]. However, high percentage of insulin release (above 75\%) has been observed under acidic conditions ( $\mathrm{pH} 1.2)$ [123], resulting in a poor release in the intestinal region. This behavior is a consequence of dissociation of ionic linkages which leads to a weaker gel and release of the molecule by diffusion [123]. Lower release percentages of 
TABLE 5: Potential application of AX gels in controlled release of biomolecules and cells.

\begin{tabular}{|c|c|c|c|}
\hline AX source & Biomolecule/cell & Potential controlled-release system & Reference \\
\hline Wheat & Ovalbumin $(\mathrm{Ov})$ & $\begin{array}{l}\text { Ov-AX gels for entrapment and controlled } \\
\text { release of proteins. } 70-88 \% \text { protein release } \\
\text { as Ov/AX ratio increased ( } 24 \mathrm{~h} \text { in vitro test). }\end{array}$ & {$[36]$} \\
\hline Maize bran & Insulin and $\beta$-lactoglobulin & $\begin{array}{l}\text { AX gels for controlled release of proteins. } \\
11-18 \% \text { of protein release at the end of a } 15 \mathrm{~h} \\
\text { in vitro test. }\end{array}$ & [33] \\
\hline Maize bran & Lycopene & $\begin{array}{l}\text { Lycopene/AX gels for controlled delivery of } \\
\text { biomolecules. } 3-4 \% \text { lycopene release at the } \\
\text { end of a } 4 \mathrm{~h} \text { in vitro test. }\end{array}$ & {$[121]$} \\
\hline Maize bran & Methyl xanthine (caffeine) & $\begin{array}{l}\text { AX microparticles. } 10 \% \text { of caffeine release at a } 3 \mathrm{~h} \\
\text { in vitro test }(0.1 \mathrm{M} \mathrm{HCl}) .\end{array}$ & {$[35]$} \\
\hline $\begin{array}{l}\text { Ispaghula (Plantago } \\
\text { ovata) seed husk }\end{array}$ & $\begin{array}{l}\text { Metronidazole hydrochloride } \\
\text { (MH) }\end{array}$ & $\begin{array}{l}\text { MH-loaded calcium gelled AX microspheres for } \\
\text { extended drug delivery. } 90 \% \mathrm{MH} \text { release at a } \\
\qquad 70-80 \text { min in vitro test. }\end{array}$ & [43] \\
\hline Maize bran & Insulin & $\begin{array}{l}\text { AX microspheres as insulin carriers for colon- } \\
\text { specific drug delivery. Insulin release in the colonic } \\
\text { region of diabetic rats. }\end{array}$ & {$[34]$} \\
\hline $\begin{array}{l}\text { Maize waste water } \\
\text { (nejayote) and maize } \\
\text { bran }\end{array}$ & Insulin, Bifidobacterium & $\begin{array}{l}\text { Core-shell AX particle (AX-insulin/AX- } \\
\text { Bifidobacterium) for entrapment and delivery of } \\
\text { insulin and probiotics targeted to colon for diabetes } \\
\text { treatment. } 76 \% \text { insulin release in colonic region } \\
\text { using a simulator of the gastrointestinal tract (Simgi). }\end{array}$ & [32] \\
\hline
\end{tabular}

molecules (10-24\%) have been observed using AX gels [32, 35] which could assure the release of a higher content of the molecule in the target site.

Swelling behavior is an important characteristic of hydrogels for its application as controlled-release systems. Hydrophilic groups of the polymer network lead to water uptake, resulting in a swelled gel that favors the release of the entrapped molecule by diffusion [124]. However, this also could be a disadvantage when gels exhibit high degrees of swelling because of the complete release of the molecule before reaching its target site. Swelling of alginate gels depends on the $\mathrm{pH}$ medium as they are sensible to ionic strength changes. In acidic conditions ( $\mathrm{pH} 1.2$ ), alginate gels have shown low swelling degrees, while in alkaline medium ( $\mathrm{pH}$ 6.8-7.4) the swelling degree increases and then decreases abruptly because of the complete disintegration of the gel. In alkaline conditions, an ion exchange occurs between monovalent and divalent ions, resulting in the breakup of the gel network favoring swelling and subsequent degradation [124]. On the other hand, covalent AX gels resist $\mathrm{pH}$ changes so its swelling behavior is not affected by ionic charges. Among other factors, the swelling degree of AX depends on the content of FA as higher values of FA form higher content of cross-links leading to a more compact structure. The more compact the structure of the gel network, the less the capability of the gel to absorb water [25]. Thus, the swelling behavior of gels affects directly in drug release. In this regard, the percentage of drug (celecoxib) released from alginate gels in acidic medium was near 25\%, while in alkaline conditions a complete release was observed at $8 \mathrm{~h}$ [124]. Similar values were reported for AX gels where $24 \%$ of insulin was released in stomach conditions, while $75 \%$ was released in the colon [32].
Iravani et al. [35] encapsulated methyl xanthine in AX gels and evaluated its release under acidic $\mathrm{pH}(\mathrm{HCl} 0.1 \mathrm{M})$ in order to predict the behavior of the gels in the gastrointestinal tract. The results indicated that only $10 \%$ of caffeine is released at the beginning of a $3 \mathrm{~h}$ test. This suggests that a minimum of active molecules would be released in the stomach, while the rest of the drug could be dissolved later in the colon.

Recently, studies performed in vivo confirmed that insulin encapsulated in AX gels can be released into the colon [34]. In this study, insulin encapsulated in AX gels was administered to diabetic rats. The results showed a decrease in blood glucose levels, which suggest that insulin was released and absorbed in the colon of rats and maintains its functionality. The above results confirm that AX gels can transport the hormone through the gastrointestinal tract to the colon and to release it at this point, so they could be used as carriers for colon-specific drug delivery.

3.4.3. Prebiotics. AX can be degraded by the colonic microbiota; however, the gelling process involves the cross-linking of the polysaccharide. Therefore, when discussing about the use of AX gels as colon-specific drug delivery systems, it is important to understand the impact of the gelling process on its degradation by the colonic microbiota. In this regard, an efficient release of the administered drug in the target site will depend on the capacity of the intestinal microbiota to ferment the gels.

A combination of several specific enzymes is necessary for the complete degradation of AX (Figure 7). Among the main enzymes participating in its degradation are endo-14 - $\beta$-xylanases (commonly called xylanases) which cleave the xylose backbone randomly to shorter fragments and $\beta$ xylosidases that attack the nonreducing ends of the xylose 


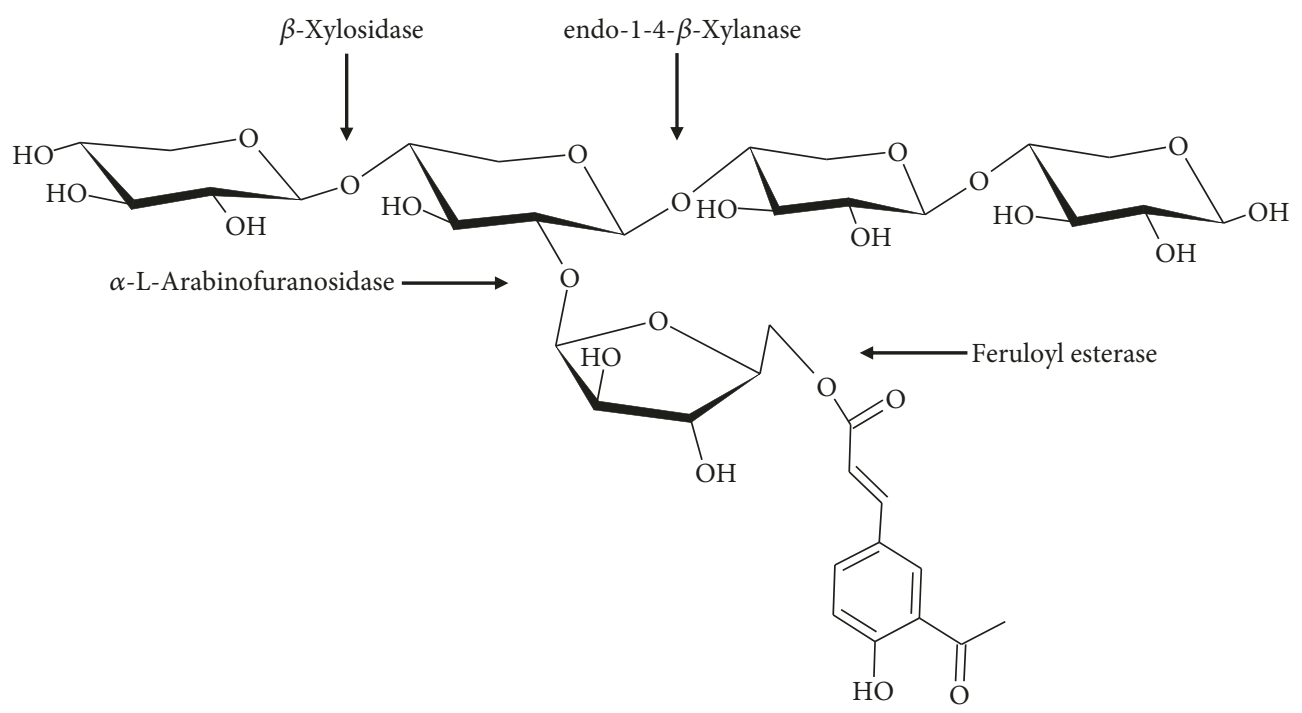

FIgURE 7: Sites of action of enzymes involved in AX degradation.

chain [125]. Other enzymes as $\alpha$-L-arabinofuranosidades detach the arabinose residues from the xylan backbone, while FA esterases are needed to release the FA residues from AX [12]. The combination of these enzymes results in the transformation of AX to shorter fragments known as AXOS [12]. AX and AXOS degradation exhibits a bifidogenic effect by the increase of the Bifidobacterium population [12, 39].

The cross-linking of AX reduces the fermentation rate in comparison with the non-cross-linked molecule. The crosslinks limit the access of bacterial enzymes for degrading the xylose chain. In addition, the cross-linking promotes a selective degradation, limiting the growth of Bacteroides. This bacterial genus does not produce the endoxylanases necessary to degrade the xylan chain, resulting in the incomplete degradation of the polysaccharide and therefore in a limited growth of these bacteria. In this regard, the selective degradation limits the growth of bacteria that are not considered beneficial at all, but it may favor the growth of bacteria that are so [10].

In a recent study, the ability of AX gels to modulate the gut microbiota and lipid metabolism in high-fat dietinduced obese rats was evaluated. The results showed that administration of a high-fat diet with AX gels increased the levels of Bifidobacteria and decreased those of Bacteroides in comparison with the high-fat diet and control groups. Moreover, the addition of AX to high-fat diet resulted in smaller adipocytes in comparison with the control and high-fat diet groups as was observed by histological analyses of the subcutaneous adipose tissue. These findings suggest the potential prebiotic properties of AX gels by the modulation of microbiota and antiobesity effect in high-fat dietinduced obese rats [126].

Recently, the degradation of AX gels at different concentrations (4 and 6\% $w / v$ ) was compared. In this study, a slower degradation in the gels of higher concentration was observed. The authors explained this behavior was attributed to the higher cross-linking density of the gels, which results in a more compact structure and limits the access for the enzymes
[9]. In this regard, it can be suggested that although a high cross-linking density decreases the fermentation rate of the AX gels, this can favor the growth of probiotic bacteria. Since the AX gels present potential prebiotic activity, they also could exhibit beneficial effects (possibly anticancer) due to the positive effects of their fermentation products (SCFA) and the increase of probiotic bacteria. Thus, the AX gel application as a colon-targeted drug delivery system would be highly possible, which would also exert effects with anticancer properties.

3.4.4. Antioxidant. The antioxidant activity of the AX has been extensively related with their FA content. Nevertheless, only few studies have explored the effect of the oxidative gelation of AX regarding this property. Although the gelling of AX involves the oxidative coupling of FA, the cross-links could be affecting in some way the antioxidant activity of the AX.

It is known that the structural features of AX affect the fermentability of AX, and therefore, it will also impact its antioxidant capacity. The fermentation patterns of AX and cross-linked AX differs in how the bacterial enzymes can degrade the molecule. In AX, $\alpha$-arabinofuranosidades begin with the detaching of the arabinosyl moieties and subsequent fermentation of the available xylose chain. On the contrary, in AX gels the arabinose moieties are firstly utilized and even when the side branches are removed, the arabinose residues are preferred over the xylan chain. This behavior is because the gel-like structure restricts the access of xylanolytic enzymes to their target sites and the xylan backbone becomes more resistant to fermentation [10]. In AXOS, the presence of FA esterified to arabinose results in a steric effect that limits the access of arabinofuranosidases to their target sites and also slows down the activity of FA esterases, leading to a decrease of the degradation and subsequent fermentation of the molecule [20].

It has been demonstrated that the presence of FA and diFA in cereal brans can be released by FA esterases present in the gastrointestinal tract (intestinal mucosa and microbiota) 
of humans and rats [127]. In this way, probiotics present in the colonic microbiota, such as Lactobacillus and Bifidobacterium, are able to produce FA esterases, enzymes required for the release of the FA moieties from AX and AXOS $[21,55,56]$. A previous study showed that the presence of two Bifidobacterium strains (B. longum and B. adolescentis) is required for the fermentation of maize bran AX gels [9]. Therefore, even if some bacteria produce the specific enzymes to release the FA moieties in $\mathrm{AX}$ gels, the cross-feeding between different bacteria producing different enzymes is highly needed for the complete degradation of AX and AX gels.

The antioxidant capacity of phenolic acids depends on uptake and further metabolism [127]. Once the FA is released, it is then metabolized by the intestinal microbiota. The FA can be transformed into phenylpropionic acids and/or vinyl phenol derivatives, which still exert certain antioxidant capacity but in a lower extent than FA. According to this, it could be stated that the metabolism of FA by bacteria will lead to a decrease in its antioxidant capacity as has been demonstrated by Snelders et al. [20]. In this study, AXOS with FA esterified to arabinose exhibited good antioxidant capacity; however, the release and subsequent metabolization of FA decreased its antioxidant capacity. The authors suggested that AXOS-bound FA will reach the colon, where FA can be released and then metabolized by FA esterases located in this region [20]. In the colonic region, FA (bound or free) as well as its metabolites can exert its antioxidant activity through a direct interaction with the colon epithelium cells and thus reduce colorectal cancer [128]. On the other hand, the absorption of di-FA from cereal bran in the gut and its subsequent reach to the vascular system was demonstrated in rats [127]. These compounds also exhibit good antioxidant capacity and may exert its beneficial effects in the colonic region as they can interact directly with the intestinal barrier.

Previous studies have shown that not only the level of FA but also the condition under which it appears (free, bond, or dimerized) impacts the antioxidant capacity of AX [129]. The presence of dimers and trimers (di-FA, tri-FA) or more complex ferulated structures decreases the antioxidant capacity of AX in comparison to the FA molecule esterified to AX. The availability of hydroxyl groups and resonance systems of FA vary according to the cross-linking position and are important factors to exert the antioxidant function of FA [87]. Thus, it is confirmed that the gelling process impacts on the antioxidant capacity of the gels.

Several studies agree that the antioxidant activity of AX decreases after the gelation process due to the formation of di-FA and tri-FA $[8,119]$. It is well documented that the formation of the AX gel involves the cross-linking of FA and consequently its oxidation. Nevertheless, the di-FA and triFA amounts produced during gelation do not compensate the FA oxidized. The remnant FA can continue to react and form higher ferulated structures [84]. Trimers and tetramers of FA have been identified in the cell wall of cereal grains, and even more complex ferulated structures are suggested [87]. Since the remaining FA could react and continue to form more complex structures, then it would be possible that such FA could keep stabilizing the free radicals and therefore exhibit antioxidant activity.
According to the above mentioned, the antioxidant activity of AX gels could be mainly related to the FA remaining after the gelation process. Thus, a higher FA content in AX gels may result in better antioxidant activity. AX with higher FA content $(6 \mu \mathrm{g} / \mathrm{mg}$ AX) can form gels with high crosslinking density and still exhibit antioxidant activity [8]. In addition, these gels preserve high amounts of FA after their gelation [130], which would allow them to exert a greater antioxidant activity.

The antioxidant activity of AX gels depends on the polysaccharide structure. The content and appearance of FA in the gel are the main factors affecting such property. AX gels with high cross-linking density can exhibit antioxidant activity. In this logical order, since the anticancer activity of AX is related to its antioxidant activity, the AX gels could also exhibit this property. However, the evaluation of the anticancer activity of AX gels and its antioxidant property relationship is necessary. These findings could allow obtaining AX gels for colon-targeted drug delivery systems with protective effect against colon cancer.

Ferulated AX exhibit prebiotic and antioxidant properties, which confer anticancer potential to the polysaccharide. Since AX gels preserve their prebiotic and antioxidant properties, they would also exert antiproliferative activity. Furthermore, the high cross-linking density of the gels would increase such properties. In recent years, the investigation of the properties of AX gels has been the focus of numerous studies due to its potential application as colon-targeted drug delivery systems. In this regard, it is necessary to evaluate the effect of gelation on the antiproliferative activity of AX. Moreover, the relationship between the structural characteristics and the functional properties of the AX gels should be investigated, particularly the effect of the high cross-linking density of the gels on their antiproliferative activity. High cross-linking density AX gels could be a good alternative for the colon-targeted drug delivery in the treatment of colon cancer.

\section{Conclusion}

This review describes the functional properties of AX and AX gels and their potential application as antioxidant and anticancer agents. Ferulated AX have prebiotic, antioxidant, and anticancer properties which can be exploited by the pharmaceutical field. Recently, the research has focused in the development of novel colon-targeted delivery systems for the treatment of colon associated diseases, such as inflammatory bowel disease, irritable bowel disease, and particularly colon cancer. Due to their gelling ability, AX have gained interest as promising polysaccharides for the designing of drug delivery systems with bioactive properties such as prebiotic, antioxidant, and anticancer.

The antioxidant and prebiotic activity of AX has been previously demonstrated. The fermentation products of AX exhibit a prebiotic effect, providing benefits for the gut health. Moreover, its antioxidant activity exerts a protective effect against the free radicals and oxidative stress. Regarding the gelling ability of AX, specific studies are needed to elucidate such beneficial effects in the AX gels. The anticancer 
activity of AX appears to be strongly related to its antioxidant and prebiotic properties. Future studies will be needed to evaluate the effect of gelation on the anticancer activity of AX gels. Furthermore, this information will allow establishing a relationship between the anticancer activity of AX with its antioxidant and prebiotic properties.

The AX gels are promising candidates for application as colon-targeted drug delivery systems for the treatment of colon cancer. However, only few studies regarding the evaluation of the antioxidant and prebiotic effect of AX gels have been conducted in vitro, and no evidence of in vivo data is available. Therefore, it is important to conduct research on the performance of in vitro and in vivo studies focusing on the effect of gelation on the biological properties (prebiotic, antioxidant, and anticancer) of AX and to elucidate the relationship between the properties of the gel by itself, not only as a mere carrier.

\section{Conflicts of Interest}

The authors declare that there is no conflict of interest regarding the publication of this article.

\section{Acknowledgments}

This research was supported by "Fondo Institucional CONACyT-Investigación en Fronteras de la Ciencia”, México (Grant FON.INST./31/2016 to Elizabeth Carvajal-Millan). The authors are pleased to acknowledge Alma C. CampaMada, Karla G. Martínez-Robinson, and Alma R. ToledoGuillén (CIAD, México).

\section{References}

[1] J. Slavin, "Why whole grains are protective: biological mechanisms," Proceedings of the Nutrition Society, vol. 62, no. 1, pp. 129-134, 2003.

[2] Y. Park, A. F. Subar, A. Hollenbeck, and A. Schatzkin, "Dietary fiber intake and mortality in the NIH-AARP diet and health study," Archives of Internal Medicine, vol. 171, no. 12, pp. 1061-1068, 2011.

[3] A. T. Kunzmann, H. G. Coleman, W. Y. Huang, C. M. Kitahara, M. M. Cantwell, and S. I. Berndt, "Dietary fiber intake and risk of colorectal cancer and incident and recurrent adenoma in the prostate, lung, colorectal, and ovarian cancer screening trial," The American Journal of Clinical Nutrition, vol. 102, no. 4, pp. 881-890, 2015.

[4] J. M. Lattimer and M. D. Haub, "Effects of dietary fiber and its components on metabolic health," Nutrients, vol. 2, no. 12, pp. 1266-1289, 2010.

[5] F. E. Ayala-Soto, S. O. Serna-Saldívar, S. García-Lara, and E. Pérez-Carrillo, "Hydroxycinnamic acids, sugar composition and antioxidant capacity of arabinoxylans extracted from different maize fiber sources," Food Hydrocolloids, vol. 35, pp. 471-475, 2014.

[6] R. K. Durham, "Effect of hydrogen peroxide on relative viscosity measurements of wheat and flour suspensions," Cereal Chemistry, vol. 2, no. 2, pp. 297-305, 1925.
[7] M. S. Izydorczyk and C. G. Biliaderis, "Cereal arabinoxylans: advances in structure and physicochemical properties," Carbohydrate Polymers, vol. 28, no. 1, pp. 33-48, 1995.

[8] R. Paz-Samaniego, M. Méndez-Encinas, J. M. Fierro-Islas et al., "Ferulated arabinoxylans recovered from low-value maize by-products: gelation and antioxidant capacity," in Ferulic Acid: Antioxidant Properties, Uses and Potential Health Benefits, W. Bryce, Ed., pp. 151-164, Nova Science Publishers, Hauppauge, Inc, 2015.

[9] A. L. Martínez-López, E. Carvajal-Millan, V. Micard et al., "In vitro degradation of covalently cross-linked arabinoxylan hydrogels by bifidobacteria," Carbohydrate Polymers, vol. 144, no. 1, pp. 76-82, 2016.

[10] M. J. Hopkins, H. N. Englyst, S. Macfarlane, E. Furrie, G. T. Macfarlane, and A. J. McBain, "Degradation of cross-linked and non-cross-linked arabinoxylans by the intestinal microbiota in children," Applied and Environmental Microbiology, vol. 69, no. 11, pp. 6354-6360, 2003.

[11] R. Paz-Samaniego, A. Rascón-Chu, F. Brown-Bojorquez et al., "Electrospray-assisted fabrication of core-shell arabinoxylan gel particles for insulin and probiotics entrapment," Journal of Applied Polymer Science, vol. 135, no. 26, article 46411, 2018.

[12] C. Grootaert, J. A. Delcour, C. M. Courtin, W. F. Broekaert, W. Verstraete, and T. van de Wiele, "Microbial metabolism and prebiotic potency of arabinoxylan oligosaccharides in the human intestine," Trends in Food Science \& Technology, vol. 18, no. 2, pp. 64-71, 2007.

[13] A. M. Neyrinck, V. F. van Hée, N. Piront et al., "Wheatderived arabinoxylan oligosaccharides with prebiotic effect increase satietogenic gut peptides and reduce metabolic endotoxemia in diet-induced obese mice," Nutrition \& Diabetes, vol. 2, no. 1, pp. 1-9, 2012.

[14] J. Wang, B. Sun, Y. Cao, and C. Wang, "Wheat bran feruloyl oligosaccharides enhance the antioxidant activity of rat plasma," Food Chemistry, vol. 123, no. 2, pp. 472-476, 2010.

[15] N. K. Badr El-Din, S. M. Abdel Fattah, D. Pan, L. Tolentino, and M. Ghoneum, "Chemopreventive activity of MGN-3/ Biobran against chemical induction of glandular stomach carcinogenesis in rats and its apoptotic effect in gastric cancer cells," Integrative Cancer Therapies, vol. 15, no. 4, pp. NP26NP34, 2016.

[16] L. Cao, X. Liu, T. Qian et al., "Antitumor and immunomodulatory activity of arabinoxylans: a major constituent of wheat bran," International Journal of Biological Macromolecules, vol. 48, no. 1, pp. 160-164, 2011.

[17] A. P. Femia, M. Salvadori, W. F. Broekaert et al., "Arabinoxylan-oligosaccharides (AXOS) reduce preneoplastic lesions in the colon of rats treated with 1,2-dimethylhydrazine (DMH)," European Journal of Nutrition, vol. 49, no. 2, pp. 127-132, 2010.

[18] W. F. Broekaert, C. M. Courtin, K. Verbeke, T. van de Wiele, W. Verstraete, and J. A. Delcour, "Prebiotic and other healthrelated effects of cereal-derived arabinoxylans, arabinoxylanoligosaccharides, and xylooligosaccharides," Critical Reviews in Food Science and Nutrition, vol. 51, no. 2, pp. 178-194, 2011.

[19] E. Noaman, N. K. Badr el-Din, M. A. Bibars, A. A. Abou Mossallam, and M. Ghoneum, "Antioxidant potential by arabinoxylan rice bran, MGN-3/biobran, represents a mechanism for its oncostatic effect against murine solid 
Ehrlich carcinoma," Cancer Letters, vol. 268, no. 2, pp. 348359, 2008.

[20] J. Snelders, H. Olaerts, E. Dornez et al., "Structural features and feruloylation modulate the fermentability and evolution of antioxidant properties of arabinoxylanoligosaccharides during in vitro fermentation by human gut derived microbiota," Journal of Functional Foods, vol. 10, pp. 1-12, 2014.

[21] D. Szwajgier and A. Jakubczyk, "Biotransformation of ferulic acid by Lactobacillus acidophilus K1 and selected Bifidobacterium strains," ACTA Scientiarum Polonorum Technologia Alimentaria, vol. 9, pp. 45-59, 2010.

[22] R. S. Govardhan Singh, P. S. Negi, and C. Radha, "Phenolic composition, antioxidant and antimicrobial activities of free and bound phenolic extracts of Moringa oleifera seed flour," Journal of Functional Foods, vol. 5, no. 4, pp. 1883-1891, 2013.

[23] A. Gulbake, A. Jain, A. Jain, A. Jain, and S. K. Jain, "Insight to drug delivery aspects for colorectal cancer," World Journal of Gastroenterology, vol. 22, no. 2, pp. 582-599, 2016.

[24] L. Zhang, Y. Sang, J. Feng, Z. Li, and A. Zhao, "Polysaccharide-based micro/nanocarriers for oral colon-targeted drug delivery," Journal of Drug Targeting, vol. 24, no. 7, pp. 579589, 2016.

[25] M. Méndez-Encinas, E. Carvajal-Millan, M. Yadav et al., "Gels of ferulated arabinoxylans: rheology, structural parameters and microstructure," in Advances in Physicochemical Properties of Biopolymers, M. A. Masuelli and D. Renard, Eds., pp. 215-228, Bentham Science Publishers, Beijing, 2017.

[26] M. S. Izydorczyk and J. E. Dexter, "Barley $\beta$-glucans and arabinoxylans: molecular structure, physicochemical properties, and uses in food products-a review," Food Research International, vol. 41, no. 9, pp. 850-868, 2008.

[27] M. S. Izydorczyk and C. G. Biliaderis, "Arabinoxylans: techonologically and nutrionally functional plant polysaccharides," in Functional Food Carbohydrates, C. G. Biliaderis and M. S. Izydorczyk, Eds., pp. 249-283, CRC Press, Boca Raton, FL, USA, 2007.

[28] M. M. Smith and R. D. Hartley, "Occurrence and nature of ferulic acid substitution of cell-wall polysaccharides in graminaceous plants," Carbohydrate Research, vol. 118, no. 1, pp. 65-80, 1983.

[29] M. R. Savitha Prashanth, R. R. Shruthi, and G. Muralikrishna, "Immunomodulatory activity of purified arabinoxylans from finger millet (Eleusine coracana, v. Indaf 15) bran," Journal of Food Science and Technology, vol. 52, no. 9, pp. 6049-6054, 2015.

[30] A. Morales-Burgos, E. Carvajal-Millan, Y. López-Franco et al., "Syneresis in gels of highly ferulated arabinoxylans: characterization of covalent cross-linking, rheology, and microstructure," Polymers, vol. 9, no. 12, 2017.

[31] M. S. Iqbal, J. Akbar, M. A. Hussain, S. Saghir, and M. Sher, "Evaluation of hot-water extracted arabinoxylans from ispaghula seeds as drug carriers," Carbohydrate Polymers, vol. 83, no. 3, pp. 1218-1225, 2011.

[32] R. Paz-Samaniego, E. Carvajal-Millan, N. Sotelo-Cruz et al., "Maize processing waste water upcycling in Mexico: recovery of arabinoxylans for probiotic encapsulation," Sustainability, vol. 8, no. 11, p. 1104, 2016.

[33] C. M. Berlanga-Reyes, E. Carvajal-Millán, J. Lizardi-Mendoza, A. Rascón-Chu, J. Marquez-Escalante, and A. L. Martínez-
López, "Maize arabinoxylan gels as protein delivery matrices," Molecules, vol. 14, no. 4, pp. 1475-1482, 2009.

[34] A. L. Martínez-López, E. Carvajal-Millan, J. Lizardi-Mendoza et al., "Matrices covalentes biodegradables para el suministro de insulina por vía oral dirigida al colon activado por la microbiota y proceso para su obtención," México, Patente mexicana No. MX/a/2015/017857, 2016.

[35] S. Iravani, C. S. Fitchett, and D. M. R. Georget, "Physical characterization of arabinoxylan powder and its hydrogel containing a methyl xanthine," Carbohydrate Polymers, vol. 85, no. 1, pp. 201-207, 2011.

[36] E. Carvajal-Millan, S. Guilbert, J. L. Doublier, and V. Micard, "Arabinoxylan/protein gels: structural, rheological and controlled release properties," Food Hydrocolloids, vol. 20, no. 1, pp. 53-61, 2006.

[37] A. Morales-Ortega, E. Carvajal-Millan, F. Brown-Bojorquez et al., "Entrapment of probiotics in water extractable arabinoxylan gels: rheological and microstructural characterization," Molecules, vol. 19, no. 3, pp. 3628-3637, 2014.

[38] S. Zhou, X. Liu, Y. Guo, Q. Wang, D. Peng, and L. Cao, "Comparison of the immunological activities of arabinoxylans from wheat bran with alkali and xylanase-aided extraction," Carbohydrate Polymers, vol. 81, no. 4, pp. 784-789, 2010.

[39] A. M. Neyrinck, S. Possemiers, C. Druart et al., "Prebiotic effects of wheat arabinoxylan related to the increase in bifidobacteria, roseburia and bacteroides/prevotella in diet-induced obese mice," PLoS One, vol. 6, no. 6, p. e20944, 2011.

[40] P. Lissoni, G. Messina, F. Brivio et al., "Modulation of the anticancer immunity by natural agents: inhibition of $\mathrm{T}$ regulatory lymphocyte generation by arabinoxylan in patients with locally limited or metastatic solid tumors," Cancer Ther$a p y$, vol. 6, pp. 1011-1016, 2008.

[41] M. Ghoneum, "From bench to bedside: the growing use of arabinoxylan rice bran (MGN-3/Biobran) in cancer immunotherapy," Austin Immunology, vol. 1, no. 2, p. 1006, 2016.

[42] S. L. Ooi, D. McMullen, T. Golombick, D. Nut, and S. C. Pak, "Evidence-based review of BioBran/MGN-3 arabinoxylan compound as a complementary therapy for conventional cancer treatment," Integrative Cancer Therapies, vol. 17, pp. 1-14, 2017.

[43] C. J. Lee, C. S. Nah, C. S. Teng, W. W. Jun, and M. Saravanan, "Spray dried calcium gelled arabinoxylan microspheres: A novel carrier for extended drug delivery," Chemical Papers, vol. 69, no. 10, 2015.

[44] M. Hanif and M. Zaman, "Thiolation of arabinoxylan and its application in the fabrication of controlled release mucoadhesive oral films," Daru Journal of Pharmaceutical Sciences, vol. 25, no. 1, p. 6, 2017.

[45] M. Zaman, M. Hanif, and M. A. Khan, "Arabinoxylan-based mucoadhesive oral films of tizanidine HCL designed and optimized using central composite rotatable design," Polymer-Plastics Technology and Engineering, vol. 57, no. 5, pp. 471-483, 2018.

[46] C. Antoine, S. Peyron, F. Mabille et al., "Individual contribution of grain outer layers and their cell wall structure to the mechanical properties of wheat bran," Journal of Agricultural and Food Chemistry, vol. 51, no. 7, pp. 2026-2033, 2003.

[47] C. Barron, A. Surget, and X. Rouau, "Relative amounts of tissues in mature wheat (Triticum aestivum L.) grain and their 
carbohydrate and phenolic acid composition," Journal of Cereal Science, vol. 45, no. 1, pp. 88-96, 2007.

[48] L. Saulnier, F. Guillon, P.-E. Sado, A.-L. Chateigner-Boutin, and X. Rouau, "Plant cell wall polysaccharides in storage organs : xylans (Food applications)," in Elsevier Reference Module in Chemistry, Molecular Sciences and Chemical Engineering, J. Reedijk, Ed., pp. 1-32, Elsevier Inc, Waltham, 2013.

[49] M. S. Izydorczyk and C. G. Biliaderis, "Effect of molecular size on physical properties of wheat arabinoxylan," Journal of Agricultural and Food Chemistry, vol. 40, no. 4, pp. 561568, 1992.

[50] L. B. Bindels, N. M. Delzenne, P. D. Cani, and J. Walter, "Towards a more comprehensive concept for prebiotics," Nature Reviews Gastroenterology \& Hepatology, vol. 12, no. 5, pp. 303-310, 2015.

[51] M. Vardakou, C. N. Palop, P. Christakopoulos, C. B. Faulds, M. A. Gasson, and A. Narbad, "Evaluation of the prebiotic properties of wheat arabinoxylan fractions and induction of hydrolase activity in gut microflora," International Journal of Food Microbiology, vol. 123, no. 1-2, pp. 166-170, 2008.

[52] S. Macfarlane, G. T. Macfarlane, and J. H. Cummings, "Review article: prebiotics in the gastrointestinal tract," Alimentary Pharmacology \& Therapeutics, vol. 24, no. 5, pp. 701-714, 2006.

[53] J. M. W. Wong, R. de Souza, C. W. C. Kendall, A. Emam, and D. J. A. Jenkins, "Colonic health: fermentation and short chain fatty acids," Journal of Clinical Gastroenterology, vol. 40, no. 3, pp. 235-243, 2006.

[54] H. C. Lee, A. M. Jenner, C. S. Low, and Y. K. Lee, "Effect of tea phenolics and their aromatic fecal bacterial metabolites on intestinal microbiota," Research in Microbiology, vol. 157, no. 9, pp. 876-884, 2006.

[55] C. Nishizawa, T. Ohta, Y. Egashira, and H. Sanada, "Ferulic acid esterase activities of typical intestinal bacteria," Food Science and Technology International, vol. 4, no. 1, pp. 94-97, 1998.

[56] J. Ou and Z. Sun, "Feruloylated oligosaccharides: structure, metabolism and function," Journal of Functional Foods, vol. 7, pp. 90-100, 2014.

[57] K. E. Bach Knudsen, "Microbial degradation of whole-grain complex carbohydrates and impact on short-chain fatty acids and health," Advances in Nutrition, vol. 6, no. 2, pp. 206-213, 2015.

[58] A. Rivière, M. Selak, D. Lantin, F. Leroy, and L. de Vuyst, "Bifidobacteria and butyrate-producing colon bacteria: importance and strategies for their stimulation in the human gut," Frontiers in Microbiology, vol. 7, 2016.

[59] T. S. Nielsen, H. N. Lærke, P. K. Theil et al., "Diets high in resistant starch and arabinoxylan modulate digestion processes and SCFA pool size in the large intestine and faecal microbial composition in pigs," British Journal of Nutrition, vol. 112, no. 11, pp. 1837-1849, 2014.

[60] N. Yacoubi, F. van Immerseel, R. Ducatelle, L. Rhayat, E. Bonnin, and L. Saulnier, "Water-soluble fractions obtained by enzymatic treatment of wheat grains promote short chain fatty acids production by broiler cecal microbiota," Animal Feed Science and Technology, vol. 218, no. 1, pp. 110-119, 2016.

[61] P. Truchado, E. Hernandez-Sanabria, B. N. Salden et al., "Long chain arabinoxylans shift the mucosa-associated microbiota in the proximal colon of the simulator of the human intestinal microbial ecosystem (M-SHIME)," Journal of Functional Foods, vol. 32, pp. 226-237, 2017.

[62] M. Srinivasan, A. R. Sudheer, and V. P. Menon, "Ferulic acid: therapeutic potential through its antioxidant property," Journal of Clinical Biochemistry and Nutrition, vol. 40, no. 2, pp. 92-100, 2007.

[63] J.-C. Cheng, F. Dai, B. Zhou, L. Yang, and Z.-L. Liu, “Antioxidant activity of hydroxycinnamic acid derivatives in human low density lipoprotein: mechanism and structure-activity relationship," Food Chemistry, vol. 104, no. 1, pp. 132-139, 2007.

[64] J. J. Reiners Jr, R. Clift, and P. Mathieu, "Suppression of cell cycle progression by flavonoids; dependence on the aryl hydrocarbon receptor," Carcinogenesis, vol. 20, no. 8, pp. 1561-1566, 1999.

[65] C. A. Rice-Evans, N. J. Miller, and G. Paganga, "Structureantioxidant activity relationships of flavonoids and phenolic acids," Free Radical Biology é Medicine, vol. 20, no. 7, pp. 933-956, 1996.

[66] A. Kolakowska and G. Bartosz, "Oxidation of food components: an introduction," in Food Oxidants and Antioxidants. Chemical, Biological and Functional Properties, G. Bartosz, Ed., pp. 1-17, CRC Press, Boca Raton, FL, USA, 2014.

[67] F. Shahidi and A. Chandrasekara, "Hydroxycinnamates and their in vitro and in vivo antioxidant activities," Phytochemistry Reviews, vol. 9, no. 1, pp. 147-170, 2010.

[68] S. Kamboj and V. Rana, "Physicochemical, rheological and antioxidant potential of corn fiber gum," Food Hydrocolloids, vol. 39, no. 1, pp. 1-9, 2014.

[69] J. Wang, B. Sun, Y. Cao, H. Song, and Y. Tian, "Inhibitory effect of wheat bran feruloyl oligosaccharides on oxidative DNA damage in human lymphocytes," Food Chemistry, vol. 109, no. 1, pp. 129-136, 2008.

[70] R. L. Prior, X. Wu, and K. Schaich, "Standardized methods for the determination of antioxidant capacity and phenolics in foods and dietary supplements," Journal of Agricultural and Food Chemistry, vol. 53, no. 10, pp. 4290-4302, 2005.

[71] P. Anand, A. B. Kunnumakara, C. Sundaram et al., "Cancer is a preventable disease that requires major lifestyle changes," Pharmaceutical Research, vol. 25, no. 9, pp. 2097-2116, 2008.

[72] A. Sudhakar, "History of cancer, ancient and modern treatment methods," Journal of Cancer Science \& Therapy, vol. 1, no. 2, pp. i-iv, 2009.

[73] J. Qiao, Z. Liu, and Y. X. Fu, "Adapting conventional cancer treatment for immunotherapy," Journal of Molecular Medicine, vol. 94, no. 5, pp. 489-495, 2016.

[74] M. Glei, T.Hofmann, K. Küster, J.Hollmann, M. G. Lindhauer, and B. L. Pool-Zobel, "Both wheat (Triticum aestivum) bran arabinoxylans and gut flora-mediated fermentation products protect human colon cells from genotoxic activities of 4-hydroxynonenal and hydrogen peroxide," Journal of Agricultural and Food Chemistry, vol. 54, no. 6, pp. 2088-2095, 2006.

[75] N. K. Badr el-Din, E. Noaman, and M. Ghoneum, "In vivo tumor inhibitory effects of nutritional rice bran supplement MGN-3/biobran on Ehrlich carcinoma-bearing mice," Nutrition and Cancer, vol. 60, no. 2, pp. 235-244, 2008.

[76] M. Ghoneum and S. Gollapudi, "Synergistic apoptotic effect of arabinoxylan rice bran (MGN-3/biobran) and curcumin (turmeric) on human multiple myeloma cell line U266 in vitro," Neoplasma, vol. 58, no. 2, pp. 118-123, 2011. 
[77] M. Ghoneum, N. K. Badr el-Din, D. A. Ali, and M. A. el-Dein, "Modified arabinoxylan from rice bran, MGN-3/biobran, sensitizes metastatic breast cancer cells to paclitaxel in vitro," Anticancer Research, vol. 34, no. 1, pp. 81-87, 2014.

[78] M. C. Figueroa-Espinoza and X. Rouau, "Oxidative crosslinking of pentosans by a fungal laccase and horseradish peroxidase: mechanism of linkage between feruloylated arabinoxylans," Cereal Chemistry, vol. 75, no. 2, pp. 259-265, 1998.

[79] T. Geissman and H. Neukom, "On the composition of the water-soluble wheat flour pentosans and their oxidative gelation," Lebensmittel-Wissenschaft \& Technologie, vol. 6, no. 1, pp. 59-62, 1973.

[80] D. M. R. Georget, A. Ng, A. C. Smith, and K. W. Waldron, "Thermal characterisation of oxidatively cross-linked American corn bran hemicellulose," Journal of the Science of Food and Agriculture, vol. 79, no. 3, pp. 481-483, 1999.

[81] R. C. Hoseney and J. M. Faubion, "A mechanism of the oxidative gelation of wheat flour," Cereal Chemistry, vol. 58, no. 5, pp. 421-424, 1981.

[82] M. S. Izydorczyk, C. G. Biliaderis, and W. Bushuk, "Oxidative gelation studies of water-soluble pentosans from wheat," Journal of Cereal Science, vol. 11, no. 2, pp. 153-169, 1990.

[83] A. Ng, R. N. Greenshields, and K. W. Waldron, "Oxidative cross-linking of corn bran hemicellulose: formation of ferulic acid dehydrodimers," Carbohydrate Research, vol. 303, no. 4, pp. 459-462, 1997.

[84] E. Carvajal-Millan, V. Landillon, M. H. Morel, X. Rouau, J. L. Doublier, and V. Micard, "Arabinoxylan gels: impact of the feruloylation degree on their structure and properties," Biomacromolecules, vol. 6, no. 1, pp. 309-317, 2005.

[85] E. Carvajal-Millan, S. Guilbert, M. Morel, and V. Micard, "Impact of the structure of arabinoxylan gels on their rheological and protein transport properties," Carbohydrate Polymers, vol. 60, no. 4, pp. 431-438, 2005.

[86] E. Vansteenkiste, C. Babot, X. Rouau, and V. Micard, "Oxidative gelation of feruloylated arabinoxylan as affected by protein. Influence on protein enzymatic hydrolysis," Food Hydrocolloids, vol. 18, no. 4, pp. 557-564, 2004.

[87] M. Bunzel, "Chemistry and occurrence of hydroxycinnamate oligomers," Phytochemistry Reviews, vol. 9, no. 1, pp. 47-64, 2010.

[88] E. Carvajal-Millan, B. Guigliarelli, V. Belle, X. Rouau, and V. Micard, "Storage stability of laccase induced arabinoxylan gels," Carbohydrate Polymers, vol. 59, no. 2, pp. 181-188, 2005.

[89] C. M. Courtin, K. Swennen, W. F. Broekaert et al., "Effects of dietary inclusion of xylooligo-saccharides, arabinoxylooligosaccharides and soluble arabinoxylan on the microbial composition of caecal contents of chickens," Journal of the Science of Food and Agriculture, vol. 88, no. 14, pp. 2517-2522, 2008.

[90] P. van den Abbeele, P. Gérard, S. Rabot et al., "Arabinoxylans and inulin differentially modulate the mucosal and luminal gut microbiota and mucin-degradation in humanized rats," Environmental Microbiology, vol. 13, no. 10, pp. 2667-2680, 2011.

[91] B. Damen, J. Verspreet, A. Pollet, W. F. Broekaert, J. A. Delcour, and C. M. Courtin, "Prebiotic effects and intestinal fermentation of cereal arabinoxylans and arabinoxylan oligosaccharides in rats depend strongly on their structural properties and joint presence," Molecular Nutrition \& Food Research, vol. 55, no. 12, pp. 1862-1874, 2011.

[92] H. Chen, Y. Fu, X. Jiang et al., "Arabinoxylan activates lipid catabolism and alleviates liver damage in rats induced by high-fat diet," Journal of the Science of Food and Agriculture, vol. 98, no. 1, pp. 253-260, 2018.

[93] A. Pérez-Martínez, J. Valentín, L. Fernández et al., “Arabinoxylan rice bran (MGN-3/Biobran) enhances natural killer cell-mediated cytotoxicity against neuroblastoma in vitro and in vivo," Cytotherapy, vol. 17, no. 5, pp. 601-612, 2015.

[94] N. K. Badr El-Din, D. A. Ali, R. Othman, and M. Ghoneum, "Prevention of hepatocarcinogenesis in rats by arabinoxylan rice bran, MGN-3/Biobran," in Proceedings: AACR 107th Annual Meeting, New Orleans, LA, USA, April 2016.

[95] M. Ghoneum, "Anti-HIV activity in Vitroof MGN-3, an activated Arabinoxylane from rice bran," Biochemical and Biophysical Research Communications, vol. 243, no. 1, pp. 25-29, 1998.

[96] M. Ghoneum and A. Jewett, "Production of tumor necrosis factor-alpha and interferon-gamma from human peripheral blood lymphocytes by MGN-3, a modified arabinoxylan from rice bran, and its synergy with interleukin-2 in vitro," Cancer Detection and Prevention, vol. 24, no. 4, pp. 314-324, 2000.

[97] B. V. Dons'koi, V. P. Chernyshov, and D. V. Osypchuk, "Measurement of NK activity in whole blood by the CD69 up-regulation after co-incubation with $\mathrm{K} 562$, comparison with NK cytotoxicity assays and CD107a degranulation assay," Journal of Immunological Methods, vol. 372, no. 1-2, pp. 187-195, 2011.

[98] J. Clausen, B. Vergeiner, M. Enk, A. L. Petzer, G. Gastl, and E. Gunsilius, "Functional significance of the activationassociated receptors CD25 and CD69 on human NK-cells and NK-like T-cells," Immunobiology, vol. 207, no. 2, pp. 85-93, 2003.

[99] M. Ghoneum and S. Abedi, "Enhancement of natural killer cell activity of aged mice by modified arabinoxylan rice bran (MGN-3/Biobran)," Journal of Pharmacy and Pharmacology, vol. 56, no. 12, pp. 1581-1588, 2004.

[100] Y. Asano, K. Kaneda, J. Hiragushi, T. Tsuchida, and K. Higashino, "The tumor-bearing state induces augmented responses of organ-associated lymphocytes to high-dose interleukin-2 therapy in mice," Cancer Immunology, Immunotherapy, vol. 45, no. 2, pp. 63-70, 1997.

[101] D. Cholujova, J. Jakubikova, B. Czako et al., "MGN-3 arabinoxylan rice bran modulates innate immunity in multiple myeloma patients," Cancer Immunology, Immunotherapy, vol. 62, no. 3, pp. 437-445, 2013.

[102] K. Ogawa, M. Takeuchi, and N. Nakamura, "Immunological effects of partially hydrolyzed arabinoxylan from corn husk in mice," Bioscience, Biotechnology, and Biochemistry, vol. 69, no. 1, pp. 19-25, 2005.

[103] H. Arase, N. Arase, and T. Saito, "Interferon gamma production by natural killer (NK) cells and NK1.1+ T cells upon NKR-P1 cross-linking," Journal of Experimental Medicine, vol. 183, no. 5, pp. 2391-2396, 1996.

[104] D. Dieckmann, H. Plottner, S. Berchtold, T. Berger, and G. Schuler, "Ex vivo isolation and characterization of $\mathrm{CD} 4{ }^{+} \mathrm{CD} 25^{+} \mathrm{T}$ cells with regulatory properties from human blood," Journal of Experimental Medicine, vol. 193, no. 11, pp. 1303-1310, 2001. 
[105] H. Arase, N. Arase, and T. Saito, "Fas-mediated cytotoxicity by freshly isolated natural killer cells," Journal of Experimental Medicine, vol. 181, no. 3, pp. 1235-1238, 1995.

[106] K. Suk, Y. H. Kim, I. Chang et al., "IFN $\alpha$ sensitizes ME-180 human cervical cancer cells to TNF $\alpha$-induced apoptosis by inhibiting cytoprotective NF- $\kappa \mathrm{B}$ activation," FEBS Letters, vol. 495, no. 1-2, pp. 66-70, 2001.

[107] T. Sasagawa, M. Hlaing, and T. Akaike, "Synergistic induction of apoptosis in murine hepatoma Hepa1-6 cells by IFN- $\gamma$ and TNF- $\alpha$," Biochemical and Biophysical Research Communications, vol. 272, no. 3, pp. 674-680, 2000.

[108] M. Ghoneum and S. Gollapudi, "Modified arabinoxylan rice bran (MGN-3/Biobran) enhances yeast-induced apoptosis in human breast cancer cells in vitro," Anticancer Research, vol. 25, no. 2A, pp. 859-870, 2005.

[109] M. Ghoneum and S. Gollapudi, "Modified arabinoxylan rice bran (MGN-3/Biobran) sensitizes human $\mathrm{T}$ cell leukemia cells to death receptor (CD95)-induced apoptosis," Cancer Letters, vol. 201, no. 1, pp. 41-49, 2003.

[110] R. J. Carmody and T. G. Cotter, "Signalling apoptosis: a radical approach," Redox Report, vol. 6, no. 2, pp. 77-90, 2001.

[111] E. M. van Lieshout, M. M. Bedaf, M. Pieter, C. Ekkel, W. A. Nijhoff, and W. H. Peters, "Effects of dietary anticarcinogens on rat gastrointestinal glutathione S-transferase theta 1-1 levels," Carcinogenesis, vol. 19, no. 11, pp. 20552057, 1998.

[112] B. Halliwell and S. Chirico, "Lipid peroxidation: its mechanism, measurement, and significance," The American Journal of Clinical Nutrition, vol. 57, no. 5, pp. 715S-725S, 1993.

[113] C. Pheiffer, C. Jacobs, O. Patel, S. Ghoor, C. Muller, and J. Louw, "Expression of UCP2 in Wistar rats varies according to age and the severity of obesity," Journal of Physiology and Biochemistry, vol. 72, no. 1, pp. 25-32, 2016.

[114] T. K. L. Meyvis, S. C. de Smedt, J. Demeester, and W. E. Hennink, "Influence of the degradation mechanism of hydrogels on their elastic and swelling properties during degradation," Macromolecules, vol. 33, no. 13, pp. 4717-4725, 2000.

[115] S. B. Ross-Murphy and K. P. Shatwell, "Polysaccharide strong and weak gels," Biorheology, vol. 30, no. 3-4, pp. 217-227, 1993.

[116] R. Paz-Samaniego, E. Carvajal-Millan, F. Brown-Bojorquez et al., "Gelation of arabinoxylans from maize wastewater effect of alkaline hydrolysis conditions on the gel rheology and microstructure," in Waste Water Treatment Engineering, A. P. M. Samer, Ed., pp. 101-114, InTech, Houston, TX, USA, 2015.

[117] A. L. Martínez-López, E. Carvajal-Millan, A. Rascón-Chu, J. Márquez-Escalante, and K. Martínez-Robinson, "Gels of ferulated arabinoxylans extracted from nixtamalized and non-nixtamalized maize bran: rheological and structural characteristics," CyTA - Journal of Food, vol. 11, Supplement 1, pp. 22-28, 2013.

[118] J. A. Marquez-Escalante, E. Carvajal-Millan, Y. L. LópezFranco et al., "Gels of water extractable arabinoxylans from a bread wheat variety: swelling and microstructure," in Breeding and Genetic Engineering: The Biology and Biotechnology Research, pp. 1-12, IConcept Press Ltd, USA, 2016.

[119] A. Martínez-López, E. Carvajal-Millan, M. Miki-Yoshida et al., "Arabinoxylan microspheres: structural and textural characteristics," Molecules, vol. 18, no. 4, pp. 4640-4650, 2013.

[120] R. González-Estrada, M. Calderón-Santoyo, E. CarvajalMillan et al., "Covalently cross-linked arabinoxylans films for Debaryomyces hansenii entrapment," Molecules, vol. 20, no. 6, pp. 11373-11386, 2015.

[121] A. B. Hernández-Espinoza, M. I. Piñón-Muñiz, A. RascónChu, V. M. Santana-Rodríguez, and E. Carvajal-Millan, "Lycopene/arabinoxylan gels: rheological and controlled release characteristics," Molecules, vol. 17, no. 3, pp. 24282436, 2012.

[122] A. Bayat, F. A. Dorkoosh, A. R. Dehpour et al., "Nanoparticles of quaternized chitosan derivatives as a carrier for colon delivery of insulin: ex vivo and in vivo studies," International Journal of Pharmaceutics, vol. 356, no. 1-2, pp. 259-266, 2008.

[123] C. M. Silva, A. J. Ribeiro, I. V. Figueiredo, A. R. Gonçalves, and F. Veiga, "Alginate microspheres prepared by internal gelation: development and effect on insulin stability," International Journal of Pharmaceutics, vol. 311, no. 1-2, pp. 1-10, 2006.

[124] L. Segale, L. Giovannelli, P. Mannina, and F. Pattarino, "Calcium alginate and calcium alginate-chitosan beads containing celecoxib solubilized in a self-emulsifying phase," Scientifica, vol. 2016, Article ID 5062706, 8 pages, 2016.

[125] C. M. Courtin and J. A. Delcour, "Arabinoxylans and endoxylanases in wheat flour bread-making," Journal of Cereal Science, vol. 35, no. 3, pp. 225-243, 2002.

[126] J. M. Fierro-Islas, Anti-Obesogenic and Prebiotic Effect of Arabinoxilan Gels in Rats Fed with a High-Fat Diet, [M.S. Thesis], Centro de Investigación en Alimentación y Desarrollo, A.C., 2017.

[127] M. F. Andreasen, P. A. Kroon, G. Williamson, and M. T. Garcia-Conesa, "Intestinal release and uptake of phenolic antioxidant diferulic acids," Free Radical Biology \& Medicine, vol. 31, no. 3, pp. 304-314, 2001.

[128] B. Halliwell, K. Zhao, and M. Whiteman, "The gastrointestinal tract: a major site of antioxidant action?," Free Radical Research, vol. 33, no. 6, pp. 819-830, 2000.

[129] J. Snelders, E. Dornez, J. A. Delcour, and C. M. Courtin, "Ferulic acid content and appearance determine the antioxidant capacity of arabinoxylanoligosaccharides," Journal of Agricultural and Food Chemistry, vol. 61, no. 42, pp. 1017310182, 2013.

[130] M. Méndez-Encinas, Asociación arabinoxilano-proteína $y$ efecto de la fracción proteica en la capacidad gelificacante del polisacárido, [M.S. thesis], Centro de Investigación en Alimentación y Desarrollo, A.C., 2015. 


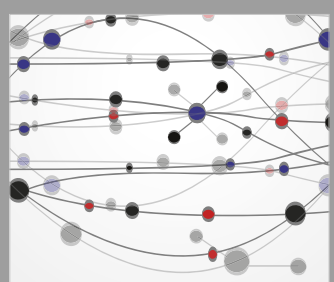

The Scientific World Journal
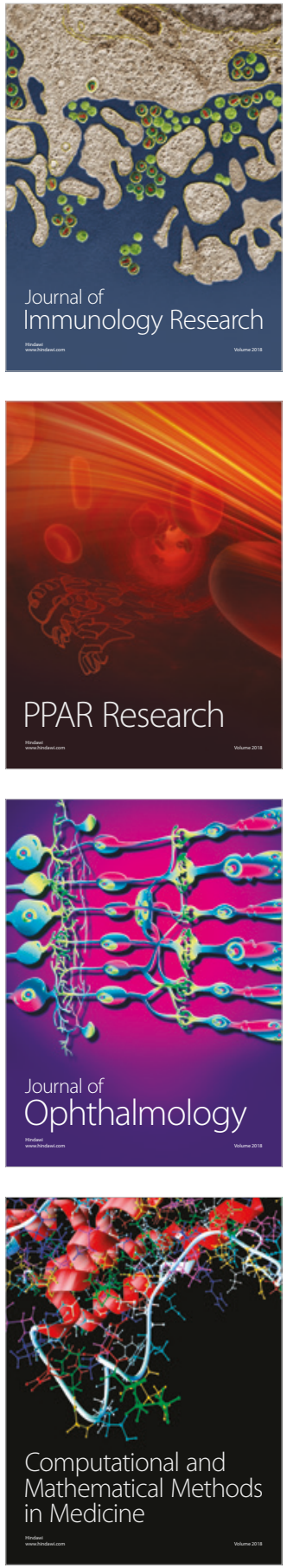

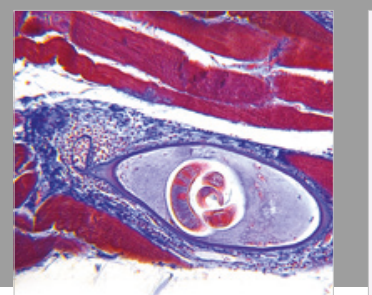

Gastroenterology Research and Practice

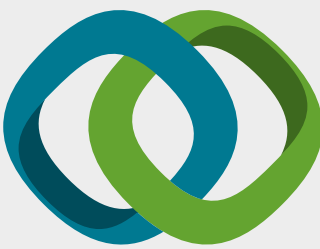

\section{Hindawi}

Submit your manuscripts at

www.hindawi.com
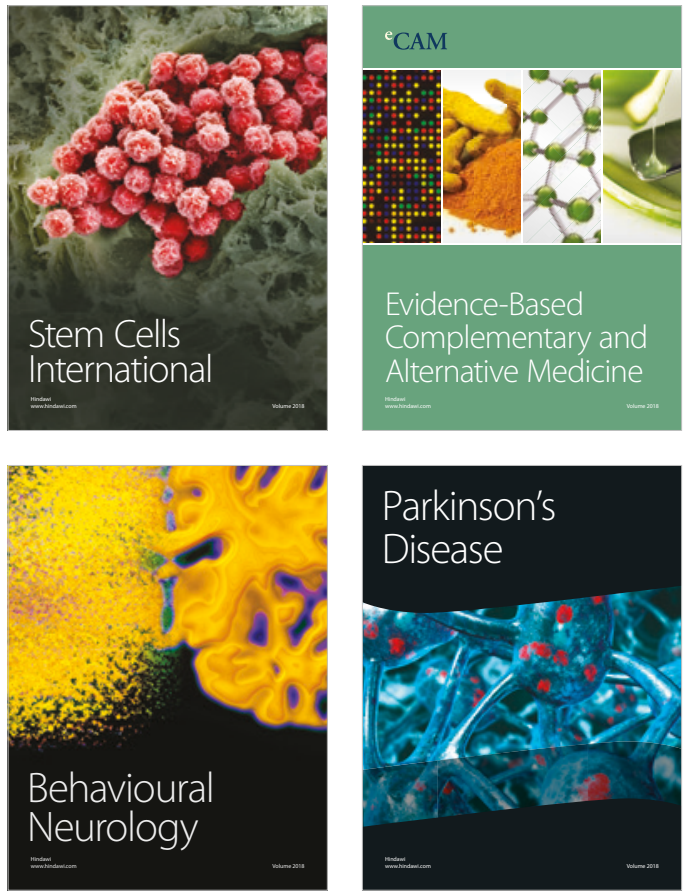

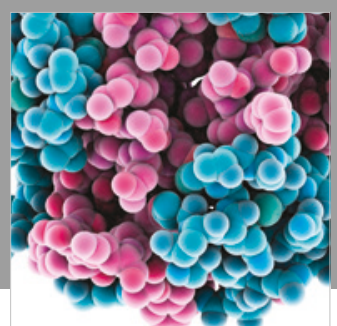

ournal of

Diabetes Research

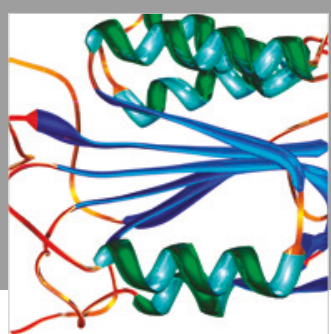

Disease Markers
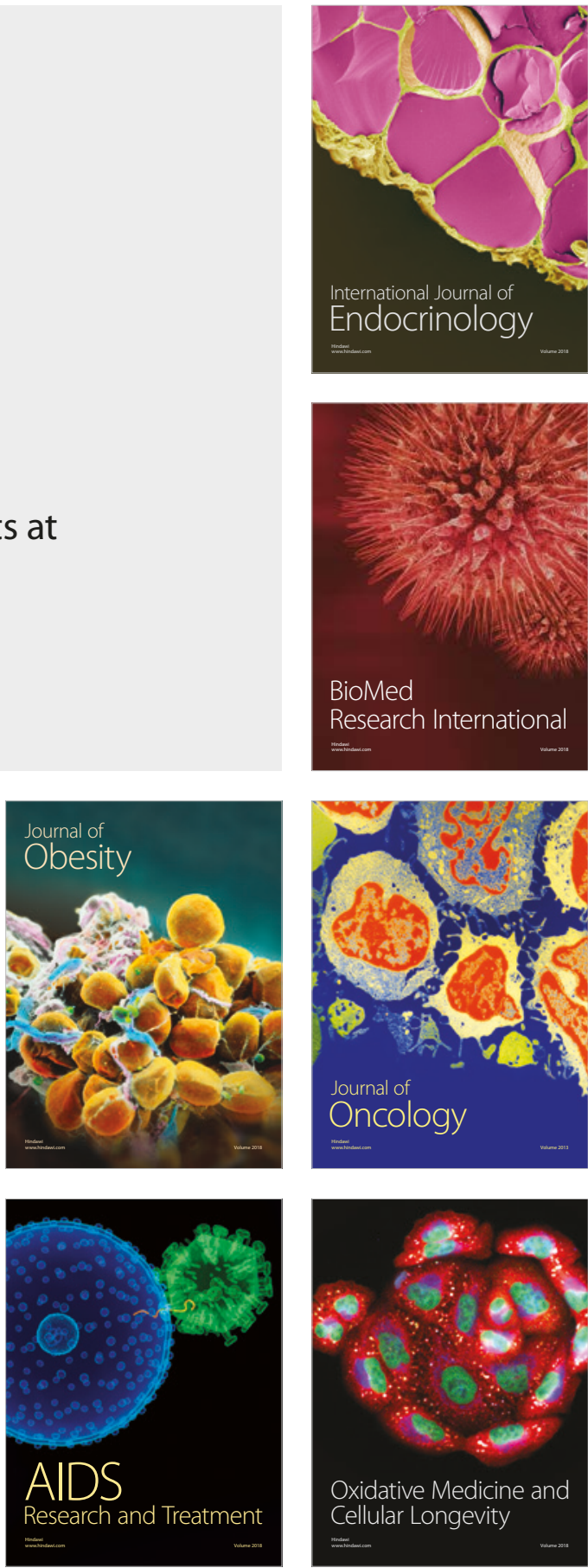